Acta Astronautica

\title{
FINAL PAYLOAD TEST RESULTS FOR THE REMOVEDEBRIS ACTIVE DEBRIS REMOVAL MISSION
}

\author{
Jason L. Forshaw ${ }^{1}$, Guglielmo S. Aglietti ${ }^{2}$ \\ Surrey Space Centre, University of Surrey, Guildford, UK
}

Thierry Salmon ${ }^{3}$

Airbus Safran Launchers, Bordeaux, France

Ingo Retat ${ }^{a}$, Mark Roe ${ }^{b}$, Christopher Burgess $^{b}$, Thomas Chabot ${ }^{c}$, Aurélien Pisseloup ${ }^{d}$

Airbus Defence and Space (DS): ${ }^{a}$ Bremen, Germany; ${ }^{b}$ Stevenage, UK; ${ }^{c}$ Toulouse, France; ${ }^{d}$ Bordeaux, France

Andy Phipps

Surrey Satellite Technology Limited (SSTL), Guildford, UK

Cesar Bernal ${ }^{f}$, François Chaumette $^{g}$, Alexandre Pollini ${ }^{h}$, Willem H. Steyn ${ }^{i}$

${ }^{f}$ Innovative Solutions In Space (ISIS), Netherlands; ${ }^{g}$ Inria, France; ${ }^{h}$ CSEM, Switzerland; ${ }^{i}$ Stellenbosch University, South Africa

\begin{abstract}
Since the beginning of the space era, a significant amount of debris has progressively been generated in space. Active Debris Removal (ADR) missions have been suggested as a way of limiting and controlling future growth in orbital space debris by actively deploying vehicles to remove debris. The European Commission FP7-sponsored RemoveDebris mission, which started in 2013, draws on the expertise of some of Europe's most prominent space institutions in order to demonstrate key ADR technologies in a cost effective ambitious manner: net capture, harpoon capture, vision-based navigation, dragsail de-orbiting.

This paper provides an overview of some of the final payload test results before launch. A comprehensive test campaign is underway on both payloads and platform. The tests aim to demonstrate both functional success of the experiments and that the experiments can survive the space environment. Space environmental tests (EVT) include vibration, thermal, vacuum or thermalvacuum (TVAC) and in some cases EMC and shock. The test flow differs for each payload and depends on the heritage of the constituent payload parts. The paper will also provide an update to the launch, expected in 2017 from the International Space Station (ISS), and test philosophy that has been influenced from the launch and prerequisite NASA safety review for the mission.

The RemoveDebris mission aims to be one of the world's first in-orbit demonstrations of key technologies for active debris removal and is a vital prerequisite to achieving the ultimate goal of a cleaner Earth orbital environment.
\end{abstract}

Keywords: debris removal, ADR, deorbiting, net, harpoon, vision-based navigation, dragsail

\section{Introduction}

$\mathrm{R}$ EMOVEDEBRIs is a low cost mission performing key active debris removal (ADR) technology demonstrations including the use of a net, a harpoon, vision-based navigation and a dragsail in a realistic space operational environment, due for

\footnotetext{
*Corresponding Author. Tel.: +44 (0)1483 686307

Email addresses: j.forshaw@surrey . ac .uk (Jason L. Forshaw), g.aglietti@surrey.ac.uk (Guglielmo S. Aglietti)

URL: www.surrey.ac.uk/ssc/ (Jason L. Forshaw)

${ }^{1}$ Consortium Dissemination Manager, Research Fellow II

${ }^{2}$ Principal Investigator, Professor of Spacecraft Structures

${ }^{3}$ Lead Mission Systems Engineer
}

launch in 2017. For the purposes of the mission CubeSats are ejected then used as targets instead of real space debris, which is an important step towards a fully operational ADR mission. This paper examines the manufacture of payload hardware and both functional and environmental testing undertaken. Many of these payload concepts have never been tested in space before, and consideration is given to aspects of the test (and design) regime that differs from a conventional satellite. A brief introduction will be given to the mission, but for full details about the concept and architecture of the mission refer to [1].

The project consortium partners with their responsibilities are given in Table 1. 
N1

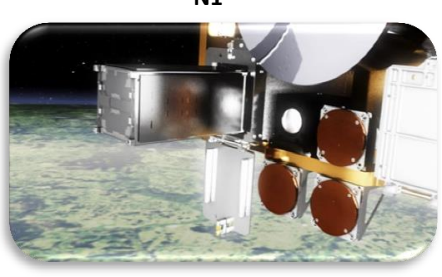

H1

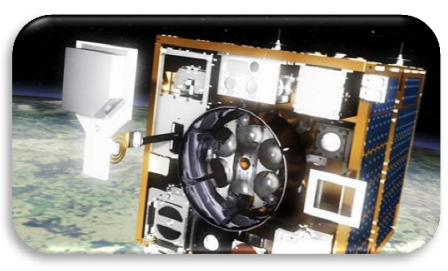

N2

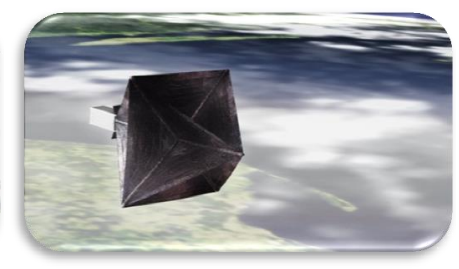

H2

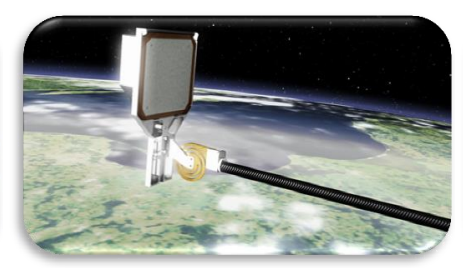

N3

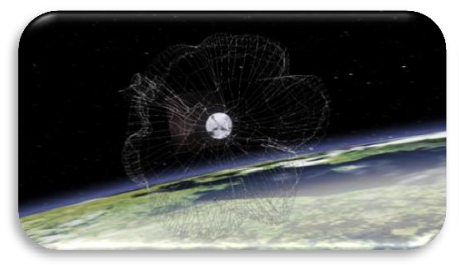

H3

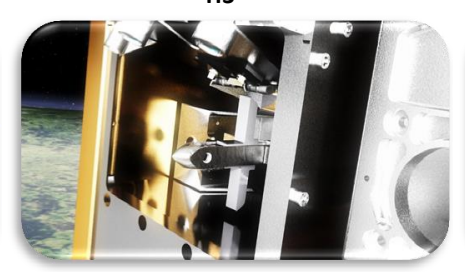

N4

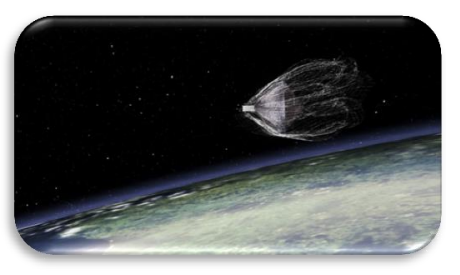

H4

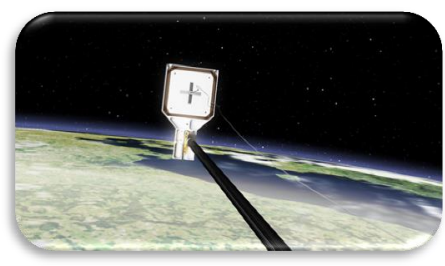

Fig. 1: Experimental Sequence. This figure shows the experimental sequences for the net (N1 to N4) and harpoon (H1 to H4): (N1) DS-1 CubeSat ejection, (N2) inflatable structure inflation, (N3) net firing, (N4) net capture, (H1) harpoon target plate extended, (H2) target plate reaches end, (H3) harpoon firing, (H4) harpoon capture.

Table 1: RemoveDebris Consortium Partners. ${ }^{\dagger}$ vision-based navigation

\begin{tabular}{l|l} 
Partner & Responsibility \\
\hline $\begin{array}{l}\text { SSC (Surrey Space Cen- } \\
\text { tre) }\end{array}$ & $\begin{array}{l}\text { Project management, Cube- } \\
\text { Sats, dragsail, harpoon target } \\
\text { assembly }\end{array}$ \\
\hline Airbus DS Germany & Net \\
\hline Airbus DS France & $\begin{array}{l}\text { Mission and systems technical } \\
\text { lead, VBN }\end{array}$ \\
\hline Airbus DS UK & Harpoon \\
\hline SSTL & $\begin{array}{l}\text { Platform technical lead, opera- } \\
\text { tions }\end{array}$ \\
\hline $\begin{array}{l}\text { ISIS (Innovative Solu- } \\
\text { tions in Space) }\end{array}$ & CubeSat deployers \\
\hline CSEM & LiDAR camera \\
\hline Inria & VBN algorithms \\
\hline Stellenbosch University & CubeSat avionics
\end{tabular}

\subsection{Literature}

One of the most active in the field of debris removal is the European Space Agency (ESA). ESA has produced a range of CleanSpace roadmaps, two of which focus on (a) space debris mitigation and (b) technologies for space debris remediation. A main part of these roadmaps is e.Deorbit, a programme spanning a host of phase studies examining removing a large ESA-owned object from space [2,3]. This initiative started with ESA's service orientated ADR (SOADR) Phase 0 study involving the analysis of a mission that could remove very heavy debris from orbit examining both the technical challenges and the business aspects of multiple ADR missions [4, 5]. Progressing on, ESA has also now completed Phase A (feasibility) and Phase B1 (PDR) studies [6, 7], with now several more mature designs now available. ESA's Satellite Servicing Building Blocks (SSBB) study originally examined remote maintenance of geostationary telecommunications satellites using a robotic arm [8]. The French space agency, CNES, is also widely involved in debris removal and has funded studies such as OTV which traded-off different ADR mission scenarios [9]. DLR's (German space agency) DEOS (Deutsche Orbital Servicing Mission) went as far in design as PDR level and aimed to rendezvous with a non-cooperative and tumbling spacecraft by means of a robotic manipulator system accommodated on a servicing satellite [10].

Regarding the development of capture technologies, there are several on-going efforts. Airbus DS capture designs include the robotic arm, net [11], and harpoon demonstrators for use in space [12]. The net, in particular, is considered by some studies to be the most robust method for debris removal, requiring the least knowledge about the target object [4]. The First European System for Active Debris Removal with Nets (ADR1EN) is testing net technologies on the ground with the aim of commercialising later on. A host of other capture technologies have also been proposed including: ion-beam shepherd [13], gecko adhesives and polyurethane foam [14, 15]. Aviospace have been involved with some ADR studies such as the Capture and De-orbiting Technologies (CADET) study which is examining attitude estimation and non-cooperative approach using a visual and infra-red system [16] and the Heavy Active Debris Removal (HADR) study that examined trade-offs for different ADR technologies, especially including flexible link capture systems [17].

Although recently there have been advances in relative space navigation, the complex application of fully uncooperative rendezvous for debris removal has not yet been attempted. Visionbased relative navigation (VBN) systems, which would be necessary for future debris removal missions are currently being developed and will be demonstrated on RemoveDebris [18, 19, 20]. Other recent research specifically related to VBN for debris removal includes: TU Dresden [21], Thales [22], Jena-Optronik [23].

A range of de-orbitation technologies have been proposed previously but few have had in-flight testing. Research includes: dragsails (InflateSail, DeOrbitSail) [24], TeSeR (which proposes an independent modular deorbitation module that attaches to the satellite before launch) [25], BETS - propellantless deorbiting 
of space debris by bare electrodynamic tethers (which proposes a tether-based removal system), solid rocket de-orbitation (proposed D-ORBIT D-SAT mission) [26].

Regarding rendezvous in space, the Autonomous Transfer Vehicle (ATV) was one of the first times a spacecraft initiated and commenced a docking manoeuvre in space in a fully autonomous mode [27]. The Engineering Test Satellite VII 'KIKU7' (ETS-VII) by JAXA in 1997 was one of the first missions to demonstrate robotic rendezvous using chaser and target satellites [28]. The AoLong-1 (ADRV) 'Roaming Dragon' satellite was also recently launched by CNSA (China National Space Administration) in 2016 in order to test target capture with a robotic arm; results are presently not available. Most recently JAXA's HTV-6 vehicle, which launched in early 2017, unsuccessfully attempted to deploy an electrodynamic tether under the Kounotori Integrated Tether Experiment (KITE) [29].

Upcoming missions to tackle debris removal include CleanSpace One by EPFL, which aims to use microsatellites with a grabber to demonstrate capture [30, 31]. The mission is still under design and launch is not foreseen for a few years. As mentioned previously, ESA's e.Deorbit will likely result in a large scale mission and is currently proposed for 2023. Of interest is AstroScale, a company based in Singapore, aiming to launch a mission with thousands of 'impact sensors' to build up knowledge of the magnitude of small fragments [32].

\subsection{Review of Mission}

On the RemoveDebris mission there are 4 main experiments that utilise the two CubeSat targets DS-1 and DS-2. The net and harpoon experimental sequences are shown in Figure 1 showing capture of the DS-1 CubeSat by a net and capture of the harpoon target plate with the harpoon. The vision-based navigation (VBN) and dragsail sequences are not re-described here; [1] gives the full details of all of the experiments.

The mission features are summarised in Table 2.

\subsection{Paper Structure}

Section 2 focuses on the nature of the launch and Section 3 summarises the test requirements and plans. Section 4 gives a quick overview of the platform. Sections 5 to 9 examine the individual payload testing including the CubeSats and deployers. Finally, Section 10 concludes the paper and outlines key contributions to the field.

\section{Launch}

The launch sequence for the RemoveDebris mission is an unconventional one. The solution uses NanoRacks as a supply agent to launch the final flight platform to the International Space Station (ISS) abroad a SpaceX cargo or Orbital ATK's Cygnus rocket. The mass of the platform, $100 \mathrm{~kg}$, represents a new business line, in that past NanoRacks launches of systems from the ISS were of a much lower mass. The launch is expected to be in late 2017, but the launch manifest and weather disruptions will dictate the final launch date. For further details about the launch refer to [35].
Table 2: RemoveDebris Mission Features. ${ }^{\dagger}$ inter-satellite link, ${ }^{*}$ payload interface unit

\begin{tabular}{|c|c|c|}
\hline Platform & $\begin{array}{l}\text { Comms } \\
\text { Power } \\
\text { Avionics }\end{array}$ & $\begin{array}{l}\mathrm{X}-50 \mathrm{M}[34] \text { with custom carbon } \\
\text { fibre additions, } 100 \mathrm{~kg} \\
\text { Sun sensors, magnetometers, } \\
\text { GPS, reaction wheels, magne- } \\
\text { torquers } \\
\text { S-band, ISL }{ }^{\dagger} \\
\text { Fixed solar array, flight battery } \\
\text { OBC dual redundant, PIU*, } \\
\text { CAN bridge }\end{array}$ \\
\hline Targets & $\begin{array}{l}\text { DS-1 CubeSat } \\
\text { (net) } \\
\text { DS-2 CubeSat } \\
\text { (VBN) } \\
\text { Deployable } \\
\text { target } \\
\text { (harpoon) }\end{array}$ & $\begin{array}{l}1 \times \text { passive CubeSat, inflatable } \\
\text { structure, low-speed deployer } \\
1 \times \text { active CubeSat with AOCS, } \\
\text { GPS, ISL }{ }^{\dagger} \text {, deployable solar } \\
\text { panels, low-speed deployer } \\
\text { Deployable boom, fixed target } \\
\text { plate }\end{array}$ \\
\hline Payloads & $\begin{array}{l}\text { Dragsail } \\
\text { Supervision } \\
\text { cameras }\end{array}$ & $\begin{array}{l}1 \times \text { net fired on DS- } 1 \text { in open- } \\
\text { loop at } 7 \mathrm{~m} \\
1 \times \text { harpoon fired on target plate } \\
\text { at } 1.5 \mathrm{~m} \\
\text { LiDAR, 2-D camera pointing } \\
\text { at DS- } 2 \text { for analysis from } 0 \text { to } \\
3000 \mathrm{~m} \\
\text { Dragsail deployable to } 9 \mathrm{~m}^{2} \text { on } \\
\text { platform } \\
2 \times \text { dual-redundant cameras } \\
\text { recording experiments }\end{array}$ \\
\hline
\end{tabular}

The use of the ISS scenario, launching to approximately $380 \mathrm{~km}$, provides greater confidence to licensing agencies as to the mission safety, as if there were any issues, all the items would de-orbit very quickly. [1] and [36] give more information about the orbital lifetime of the objects calculated using both STELA [37] and DRAMA [38], specialist end-of-life tools. They show that the main platform de-orbits within 2 years, even in case of the dragsail not deploying; smaller items, such as the CubeSats, de-orbit within a matter of months. Thus no further space debris is generated.

\subsection{Launch Sequence}

The sequence of operations can be seen in Figure 2. Before launch (1), the platform is packaged into a crew or cargo transfer bag (CTB) inside a foam 'clam shell' which protects it. After the bag is launched to the ISS (2), the bag is unpacked by astronauts that install the platform on to the Japanese experiment module (JEM) air lock (3). The air lock then depresses and the slide table extends. The platform is grappled by the JRMS, a robotic arm system (4). Finally, the robotic arm positions and releases the platform into space (5), where commissioning and main operations of the mission can commence. Naturally, the ejection trajectory ensures that the satellite will not intersect the ISS orbit at a later time. 


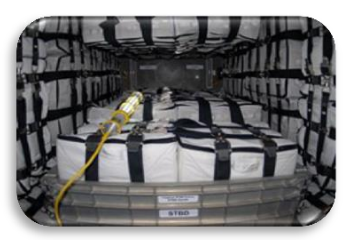

1

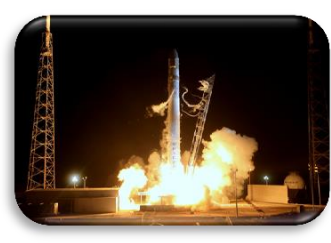

2

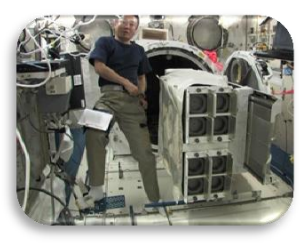

3

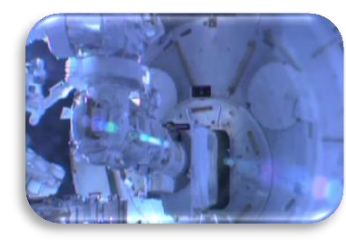

4

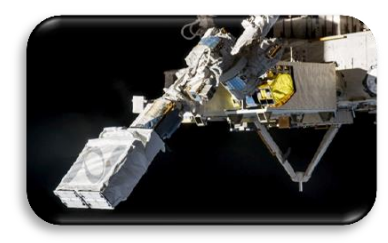

5

Fig. 2: Launch Sequence. This figure shows the launch sequences for the mission to the International Space Station (ISS). Courtesy: SpaceX, NanoRacks, NASA [33].

\section{Test Plans and Requirements}

The RemoveDebris mission follows a classical systems engineering approach at both platform and payload level, with design progressing through SRR, PDR, CDR. After AIT, a formal test readiness review (TRR) is held at both platform and payload level before functional and EVT testing is performed. For each payload, the mission develops a test plan, a set of test procedures then test results after the testing has been performed.

\subsection{Selected Key Requirements}

The full mission has several thousand requirements total, including at the mission systems level, the payload level and the subsystem level; this paper will only focus on a few of the key payload test requirements critical to the mission. These are summarised in Table 3 for each of the payloads. Throughout the remaining sections of this paper, the verification of the requirements will be examined.

\subsection{Environmental Loads}

Requirements R15 to R18 consider the environmental loads for the payloads. One factor that influences testing is the mission vibration profile, which is unconventional due to the unique launch mechanism and use of a soft shell around the platform, instead of hard-mounting it to the launch vehicle. Figure 3 shows the loads for the payloads which are $7.09 \mathrm{gRMS}$ for FM acceptance and $10.03 \mathrm{gRMS}$ for QM and PFM Acceptance. Also shown on Figure 3 are the NASA and SSTL minimum workmanship profiles, and the NanoRacks recommended profile. The platform when undergoing vibe, will use the same configuration as in flight, namely placed in a foam clam shell before being attached to the vibration table. The loads for the platform are $9.47 g R M S$ hard mounted (envelope case covering Russian launcher) and $2.56 \mathrm{gRMS}$ soft mounted.

\subsection{Influence of Launch on Design and Test}

Launching to the ISS requires three NASA safety reviews to be passed. NASA impose certain constraints on the overall mission and platform design to ensure safety to the astronauts on the ISS and these are encompassed within Requirement R19. As well as more common requirements, such as the platform not having sharp edges, several other requirements have introduced extra design effort in to the mission. These are detailed as follows.

After ejection from the ISS, the main platform is inert for up to 30 minutes before booting on. This is to protect the ISS

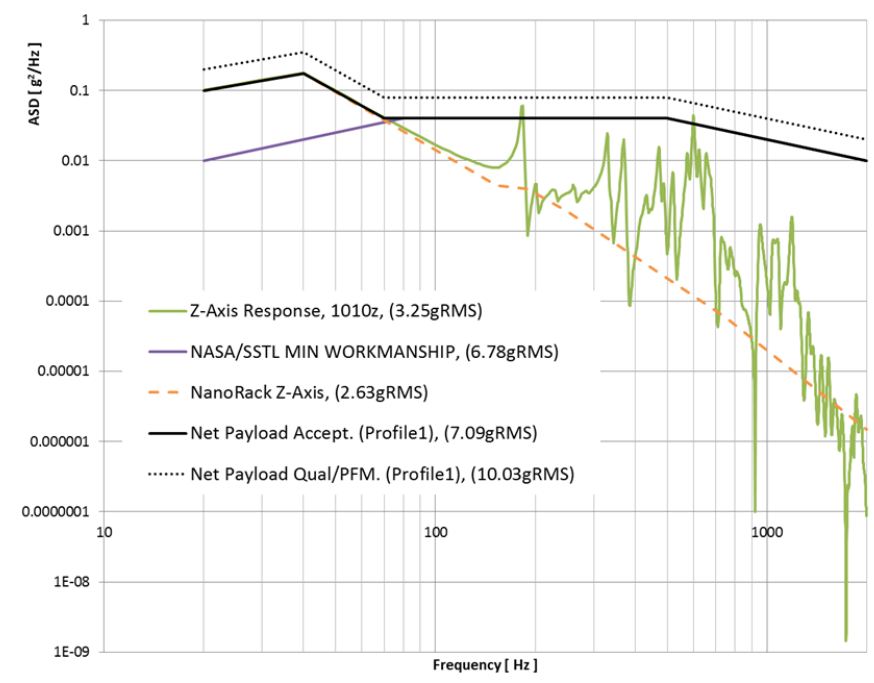

Fig. 3: Vibration Loads Profile at Payload Level. Shown for z-axis only for the net payload as an example.

from interference, or in case of any issues. All batteries on the mission must have triple electrical inhibits and thermal runaway protection. This includes the main platform battery and the two batteries in the CubeSats. The CubeSats also can only turn on when three separate deployment switches are activated, which is only physically possible when the CubeSats have left their respective pods. Mechanically, all the payloads require an inhibit.

Significant effort has been extended to ensure astronaut safety. The harpoon can only fire with an 'arm and fire' sequential command sequence (which would of course require power to the system - which already has a triple electrical inhibit). Without this command, there is no way the cold gas generator (CGG), which propels the harpoon, could be powered, and thus no way in which the harpoon could fire. Furthermore, the safety door in front of the harpoon only opens before firing and must be manually commanded to be opened. In front of the safety door is the main target plate which presents another mechanical barrier. A final mechanical barrier is the Kapton box in front of the target plate which prevents fragments of debris escaping into space during the harpoon experiment. 


\subsection{Scalability Analysis}

The authors believe the mission is a step forward in technology development and is an important step towards a fully operational ADR mission. The missions results in TRL (technology readiness level) increases in several of the technologies. The experiments on the mission are examined against 3 baselines: (a) class of $500 \mathrm{~kg}$ satellites using uncontrolled re-entry with a dragsail, (b) class of 2, $000 \mathrm{~kg}$ satellites using controlled re-entry with an active vehicle, (c) class of $8,000 \mathrm{~kg}$ satellites using controlled re-entry with an active vehicle. The latter is the largest class of satellite envisaged for scenarios such as e.Deorbit [3].

The dragsail is of high interest mainly to baseline (a). Naturally, the dragsail can't be used on the higher mass baselines, as controlled re-entry is required. Although the dragsail is not a unique concept in space, an inflatable boom that moves the dragsail away from the platform is a unique idea that requires maturation.

Regarding the net experiment, the aim would be to elevate the technology to approximately TRL 7 for baseline (a) or 5 to 7 for baselines (b) and (c). The net has not been used in this form in space before to capture space debris, although much testing has been now undertaken on the ground for this mission. The net has been designed to be scaled up for higher mass applications and is a target contender for current ESA studies as a capture technology [6].

For the harpoon, the mission aims to elevate the technology to TRL 7 for baseline (a). Although a target plate is used, the target material is realistic for use in the class of larger scale concepts (requirement R8) and much work has been done on the projectile design [1]. Furthermore, although the harpoon is being fired on a target plate, as opposed to free debris, this won't impact the harpoon design, as the ability to point at the target accurately is mainly a function of the platform AOCS accuracy. For baselines (b) and (c) the harpoon could be considered after the mission to be at TRL 5 .

For the net and harpoon, despite the on-ground testing (functional and EVT) or simulation, this is no substitute for real flight conditions in the actual vacuum, thermal and gravity environments. Hence the full flight testing of these systems develops heritage and allows the elevation of the system TRLs, such that future scaled systems with similar design are based on a functionally proven concept.

The VBN experiment is valuable across all the classes of baseline. Regardless of the size of mission, such rendezvous technology is likely to be necessary for such a mission. Simulations have already been done to test the algorithms for larger classes of satellite [19]. This mission will help validate the simulations against real data. The expected TRL is 7 for both (a) and (b) scenarios.

The mission design has tried to ensure the payloads are representative as possible for future missions and have scalability potential to larger classes. In certain cases, the mission had to give priority to practicality, satisfying regulatory (licensing) requirements or safety requirements. Either way, the mission is an important step towards a fully operational ADR mission.
Table 3: Selected Key Requirements. Note: the initial requirements specified here are mostly a simplification of, and may be an amalgamation of, the actual requirements. Some requirements may change throughout the mission to accommodate changes in operations plans, or to maintain compliance with safety reviews.

\begin{tabular}{|c|c|c|}
\hline ID & Payload & Requirement \\
\hline$R 1$ & Deployer & $\begin{array}{l}\text { Deployer shall jettison DS-1 at } 5 \mathrm{~cm} / \mathrm{s} \\
\pm 20 \% \text { for net experiment and DS-2 at } \\
2 \mathrm{~cm} / \mathrm{s} \pm 20 \% \text { for VBN experiment. }\end{array}$ \\
\hline$R 2$ & Deployer & $\begin{array}{l}\text { Deployer angular deployment accuracy } \\
\text { shall be better than } \pm 5^{\circ} \text { with nominal de- } \\
\text { ployer axis. }\end{array}$ \\
\hline$R 3$ & DS-1 & $\begin{array}{l}\text { After inflation of the DS- } 1 \text { inflatable, en- } \\
\text { velop volume shall be }<1.0 \mathrm{~m} \text { diameter. }\end{array}$ \\
\hline$R 4$ & DS-2 & $\begin{array}{l}\text { DS- } 2 \text { shall spin at rotation rate } 2 \circ / s \pm 10 \% \\
\text { on 'yaw' axis (i.e. a flat spin). }\end{array}$ \\
\hline$R 5$ & Net & $\begin{array}{l}\text { Net subsystem shall be capable of targeting } \\
\text { DS- } 1 \text { at relative distance of } 6.5 m \pm 20 \% \text {. }\end{array}$ \\
\hline$R 6$ & Net & $\begin{array}{l}\text { Net subsystem shall be tolerant to a mis- } \\
\text { alignment of } \pm 6^{\circ} \text { with respect to the target } \\
\text { deployment axis. }\end{array}$ \\
\hline$R 7$ & Harpoon & $\begin{array}{l}\text { Harpoon shall be compatible with a target } \\
\text { surface tilt of a maximum of } 5^{\circ} \text { in reference } \\
\text { to the harpoon flight axis. }\end{array}$ \\
\hline$R 8$ & Harpoon & $\begin{array}{l}\text { Harpoon shall penetrate debris composed of } \\
8 \mathrm{~mm} \text { honeycomb with } 0.5 \mathrm{~mm} \text { face sheets. }\end{array}$ \\
\hline$R 9$ & Harpoon & $\begin{array}{l}\text { Harpoon system shall capture the target } \\
\text { plate at relative distance of } 1.5 \mathrm{~m} \pm 5 \mathrm{~cm} \text {. }\end{array}$ \\
\hline$R 10$ & VBN & $\begin{array}{l}\text { LiDAR shall take a maximum of } 3000 \text { pic- } \\
\text { tures in 3D between T0 (DS-2 release) and } \\
\text { T0 +6000s. }\end{array}$ \\
\hline$R 11$ & VBN & $\begin{array}{l}\text { 2D camera shall take a maximum of } 2000 \\
\text { pictures between T0 (DS- } 2 \text { release) and T0 } \\
+24000 \mathrm{~s} \text {. }\end{array}$ \\
\hline$R 12$ & VBN & $\begin{array}{l}\text { VBN shall be able to transfer all the data } \\
\text { collected ( } 3 \mathrm{D} \text { and } 2 \mathrm{D} \text { camera) to the plat- } \\
\text { form PIU. }\end{array}$ \\
\hline$R 13$ & Dragsail & $\begin{array}{l}\text { Dragsail shall deploy to a size of } 9.0 \mathrm{~m}^{2} \\
\text { minimum. }\end{array}$ \\
\hline$R 14$ & Dragsail & Dragsail boom shall be longer than $1.0 \mathrm{~m}$. \\
\hline$R 15$ & All & $\begin{array}{l}\text { Payloads shall be able to survive mission } \\
\text { launch vibration (random and quasi-static } \\
\text { loads) levels. }\end{array}$ \\
\hline$R 16$ & All & $\begin{array}{l}\text { Payloads shall be able to withstand space } \\
\text { thermal environment, with interface temper- } \\
\text { atures with platform in the range of }\left[-20^{\circ} \text {, }\right. \\
\left.+50^{\circ}\right] \text {. }\end{array}$ \\
\hline$R 17$ & All & $\begin{array}{l}\text { Payloads shall be able to withstand space } \\
\text { vacuum environment at mission standard } \\
\text { vacuum levels. }\end{array}$ \\
\hline$R 18$ & All & $\begin{array}{l}\text { To minimise the risk of shock failure, shock } \\
\text { sensitive parts shall meet mission standard } \\
\text { shock levels. }\end{array}$ \\
\hline$R 19$ & All & $\begin{array}{l}\text { All payloads should adhere to any NASA } \\
\text { safety review requirements. }\end{array}$ \\
\hline
\end{tabular}




\section{Platform}

The RemoveDebris satellite platform is based on the X50 satellite and utilises internally developed avionics systems under the Fireworks programme [1]. In order to minimise mass the satellite structure is manufactured using honeycomb panels with either aluminium or composite face sheets. The platform can be seen in Figure 4.

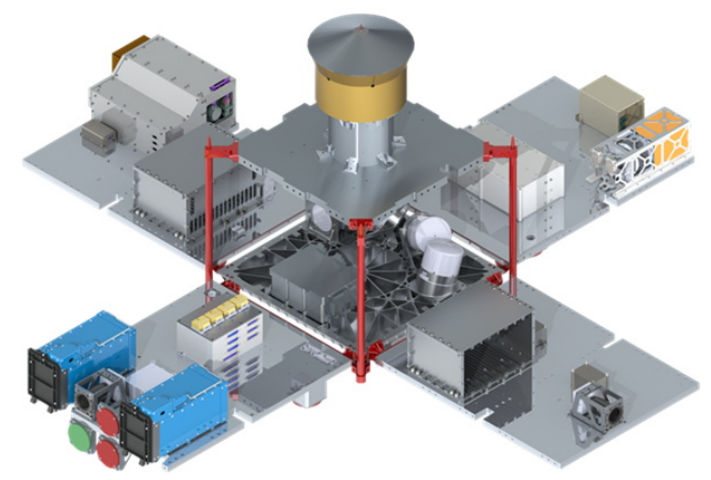

Fig. 4: Platform in Full Soft Stack Configuration. Panels are hinged open with the following subsystems. Centre panel: net payload. Bottom-left panel: $2 \times$ CubeSats and deployer pods, antennas, first supervision camera. Top-left panel: harpoon target assembly payload, first card frame. Top-right panel: VBN payload, dragsail payload. Bottom-right panel: second card frame, second supervision camera.

Once the payloads and satellite modules are delivered and accepted into assembly, integration, and test (AIT) facility the satellite will undergo a conventional environmental test (EVT) campaign comprising of: EMC testing, mass property measurements, launch box integration and strip down, vibration testing, external inspections, spacecraft functional tests, thermal vacuum testing, integration of flight battery and some flight payloads, EVT results review.

The EVT campaign will verify and validate the spacecraft and test it as a whole system. At various stages during the test campaign the satellite will undergo system level functional tests to ensure the system continues to operate as expected. The initial stages of the AIT campaign can be seen in Figure 5.

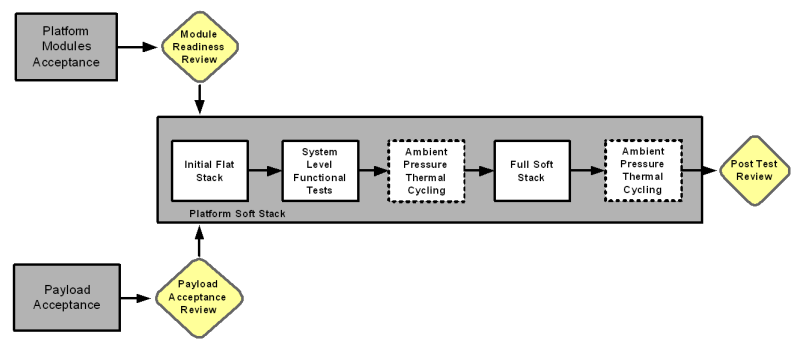

Fig. 5: AIT Flow. Showing the initial stages of the AIT campaign.

\section{Payloads - CubeSats and Deployers}

This section will focus on the testing of the two $2 \mathrm{U}$ CubeSats (each $100 \times 100 \times 227 \mathrm{~mm}$ ), used for the net and VBN demonstrations. The CubeSats are ejected from the platform then used as targets instead of real space debris, which is an important step towards a fully operational ADR mission. The CubeSats and deployers are each tested in their own framework first, before coming together for final integration and testing. Eventually the combined deployer with CubeSat inside is sent to the platform for payload integration and final testing.

In both demonstrations the ejection speed is controlled and the sequence of ejection can be seen in Figure 6. Initially, the CubeSats sit inside their pods. When the CubeSats are pushed out of the pod by a spring, they click into place at the end of the pod. The CubeSat Release System (CRS) is a burnwire that holds the CubeSat to the end of the pod. When burnt, microsprings push the CubeSats away from the pod (and platform) at a specific velocity carefully controlled through spring tuning.

Further information about the CubeSat design and operation can be found in $[24,39,40]$.

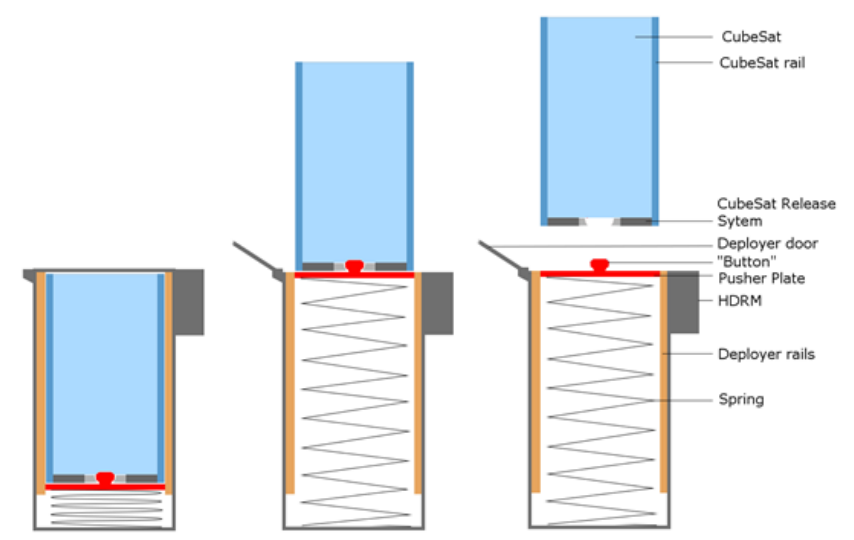

Fig. 6: Mechanism of CubeSat Ejection.

\subsection{DS-1: Net CubeSat}

In the DS-1 CubeSat, the bottom half has the avionics and the top half has the inflatable structure, which inflates shortly after the CubeSat is released from the platform in order to provide a small demonstration of inflatable technology and to provide a larger target area for the net to capture. The DS-1 structural qualification model can be seen in Figure 7 with the inflation side on the left. Two key functional testing regimes have focused on the testing of the aforementioned CRS and the inflatable system. The avionics boards, which are relatively uncomplex in the case of DS-1, are tested at a payload level before integration.

\subsection{DS-2: VBN CubeSat}

In the VBN experiment, the VBN payload on the platform will inspect the VBN CubeSat, DS-2, during a series of manoeuvres at a range of distances and in different light conditions dependent on the orbit. The CubeSat, DS-2, can be seen in Figure 8 . The avionics on-board include: the GPS board, $3 \times$ OBC boards which contain full 3-axis (3-DoF) attitude control, the EPS board, the burnwire board, an ISL (inter-satellite link) board, the camera board, and solar cells. Key functional testing focused on the testing of the: CRS, GPS and ADCS suite, ISL transmission chain. In addition, an extensive process of 


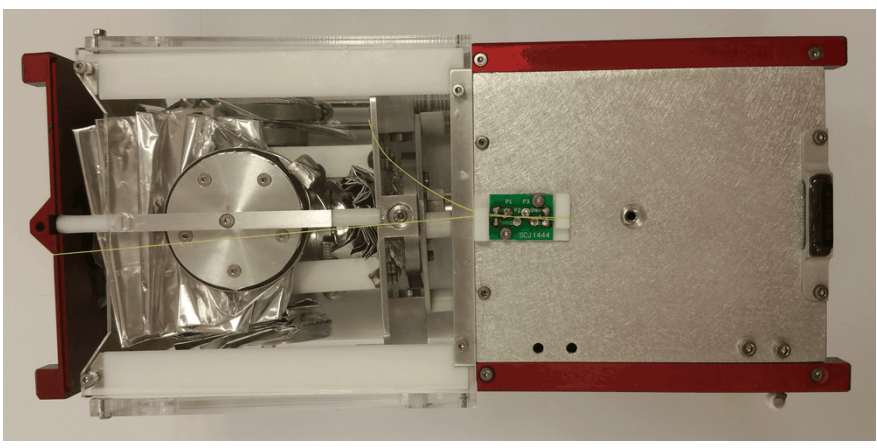

Fig. 7: DS-1: Structural Qualification Model (SQM).

systems integration testing was performed to ensure hardware and software compatibility.

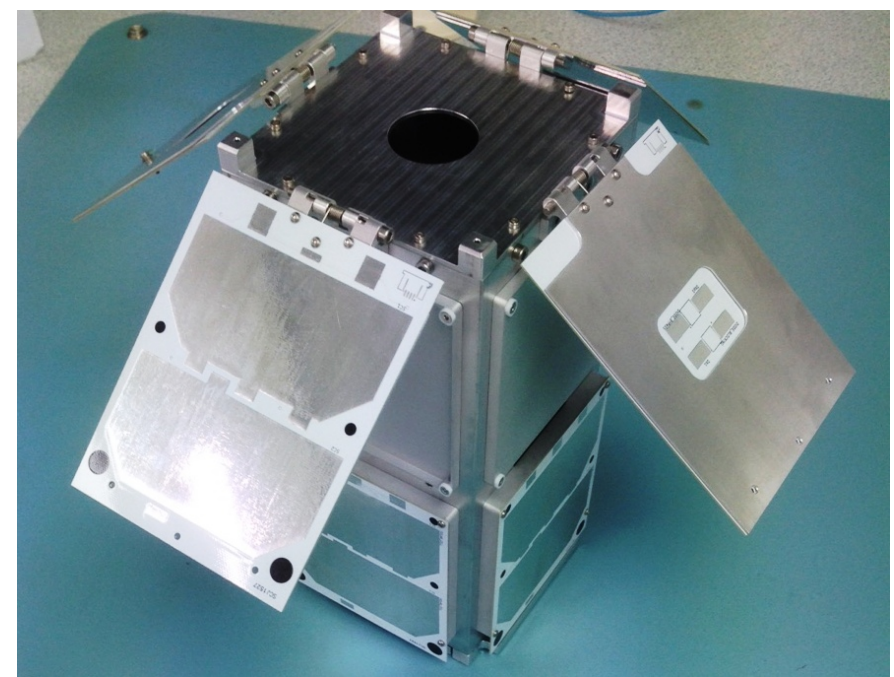

Fig. 8: DS-2: Structural Qualification Model (SQM).

\subsection{Functional Testing - Flight Software and Controls}

The CubeSat avionics are based on the QB50 avionics developed by Stellenbosch University and the Surrey Space Centre [41]. Verification of requirement R4 requires several functional tests to be undertaken: sensor orientation checks, controller gain tuning, GPS start-up and lock acquisition tests. Since the QB50 mission, there have been updates to the software suite and ground control software which is used throughout Surrey Space Centre missions (on RemoveDebris the ground station segment is only used for remote testing, not in-flight, as there is no CubeSat to ground communications). [42] gives further details about the integrated flight and ground software framework and associated testing.

\subsection{Functional Testing - Burnwires}

This testing includes the release burnwires for the DS-1 structure and DS-2 solar panels. Ensuring that the DS-1 burnwire cuts is essential to the inflatable structure being released; the DS-2 burnwire is necessary to ensure that the solar panels flip out into their characteristic cross shape. Failure of either of these will not result in experimental failure, as DS-1 would be captured anyway by the net and DS-2 is still power-safe with only the outward facing solar panels.

For the release burnwires, the testing involves application of $5 \mathrm{~V}$ at roughly $1.2 \mathrm{~A}$ to the burn resistors, which cause the burnwire to snap as shown in Figure 9. The burn system is tested firstly through a power supply, then secondarily through the main CubeSat power system (EPS). The time to burn is measured and averaged as getting the timing correct is an important part of the in-space operations sequence.

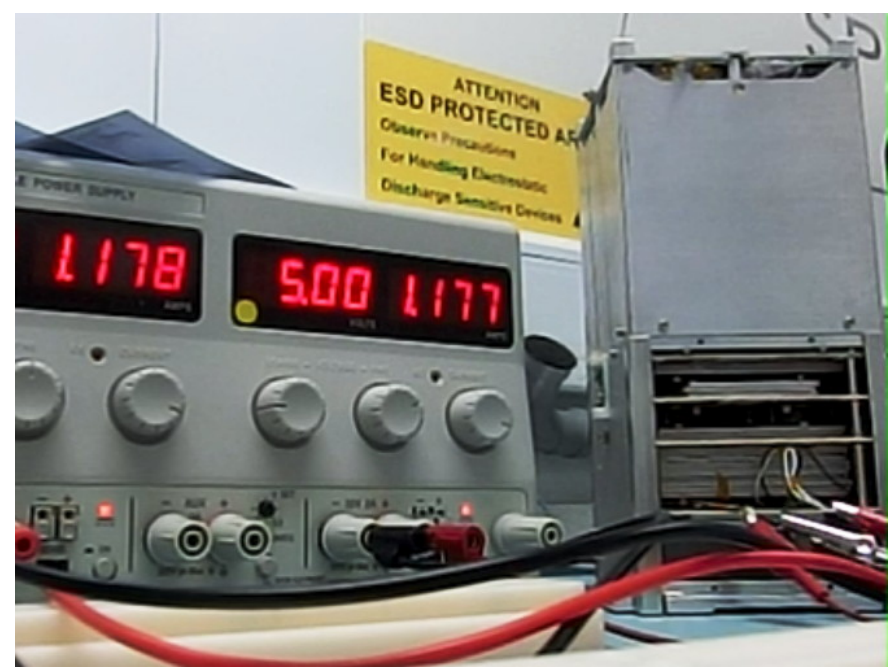

Fig. 9: DS-1: Burnwire Testing.

\subsection{Functional Testing - Inflatable Structure}

The inflatable section of DS-1 contains: the central inflation connector system, a cold gas generator (CGG) which is the inflation source, a solenoid valve. Figure 10 shows the flight model (FM) packaged inflation system both with and without sail material. The transparent side panels are only for assembly and functional test purposes; in readiness for flight these panels are replaced with metal ones. Figure 11 shows two inflation tests for the full module using an external compressed gas source, in lieu of the CGGs under procurement. Post-testing, the inflatable is measured to verify requirement R3. [43] gives further details on the inflatable design and testing methodology.
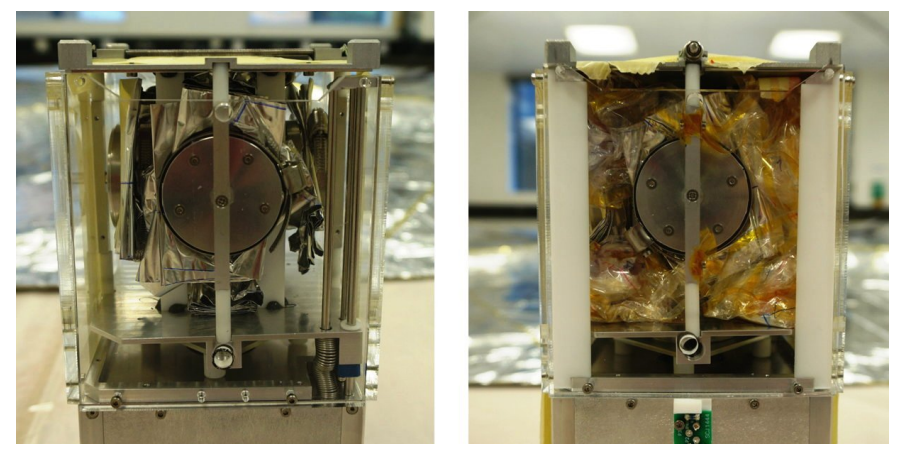

Fig. 10: DS-1: Packaged Inflation Module. 


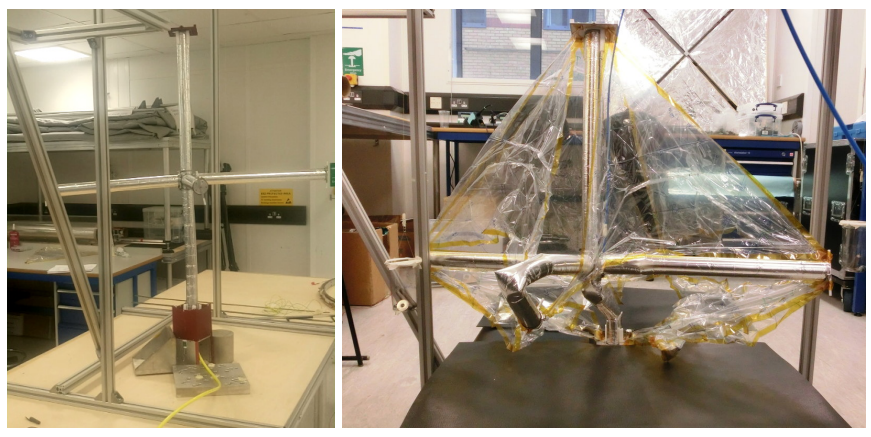

Fig. 11: DS-1: Inflatable Functional Testing. Left: inflation testing from SQM without sail segments. Right: inflation testing from SQM with sail segments attached (mid-inflation). Both tests using external gas supply line.

\subsection{Functional Testing - Deployer and CRS}

ISIPOD deployers and CRS are functionally tested separately including functional testing at cold and hot temperatures as well as characterisation of the delays due to ISIPOD hold-down and release mechanism (HDRM) and CRS actuations.

The CRS is in charge of providing the accurate deployment velocity which is critical for the success of the DS-1 and DS-2 experiments (and verification of Requirements R1 and R2). For the tuning of the CRS release springs, the release elements are fine-tuned based on the analytical results and the qualification and characterisation information. Figure 12 shows the tuning of the velocity, made by measuring the force of each pushing element.

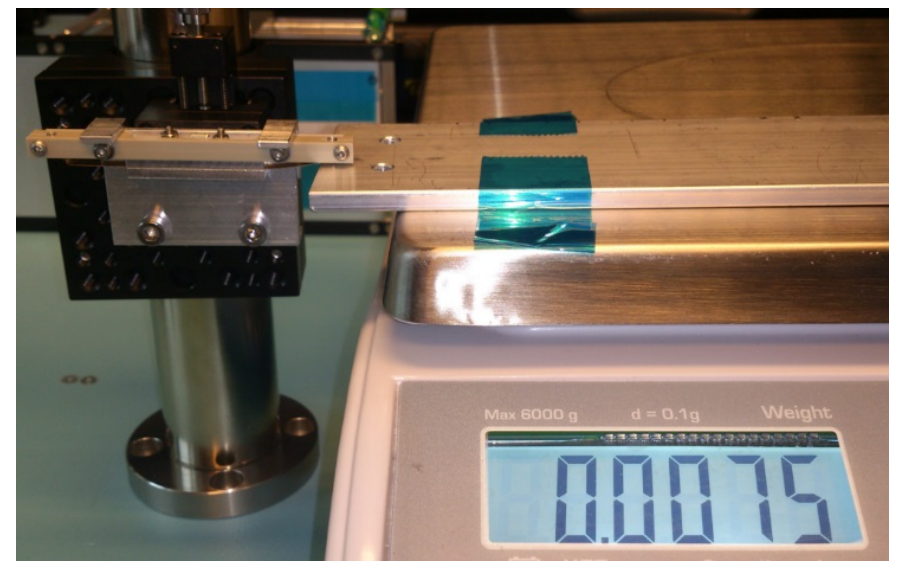

Fig. 12: Deployer and CRS: Spring Force Adjustment Setup.

Finally once the CRS is integrated on the CubeSat and this on the deployer the deployment velocity and direction are measured. A long pendulum setup together with a high speed camera are used to perform the measurement (see Figure 13). The data is post-processed via specific image software to retrieve the key information (see Figure 14) and that the deployment is within the bounds of the requirements.

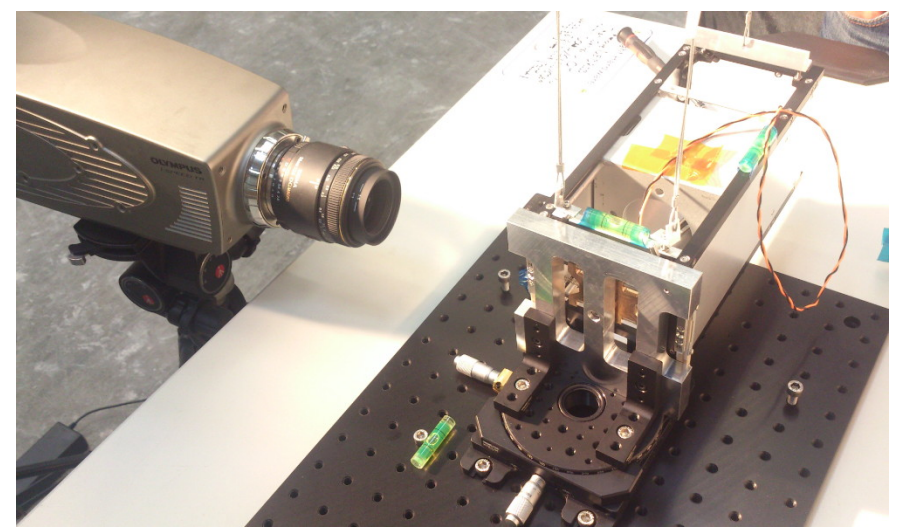

Fig. 13: Deployer and CRS: Detail of the Velocity Testing Setup. 2U CubeSat suspended on pendulum and high speed camera.

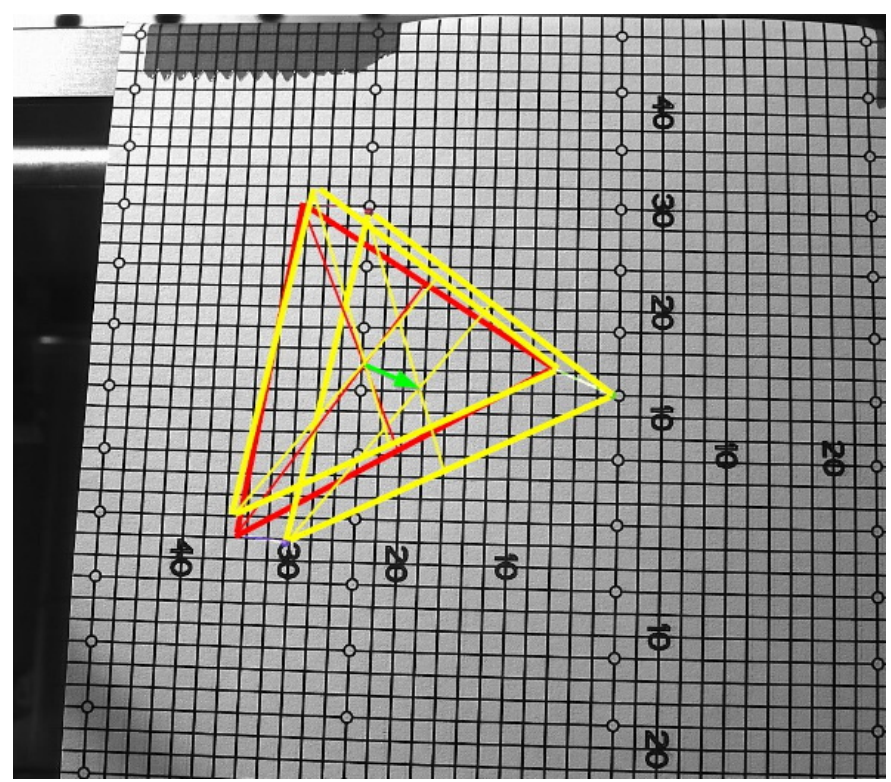

Fig. 14: Deployer and CRS: Detail of the Velocity Testing Setup. 2U CubeSat suspended on pendulum and high speed camera.

\subsection{Environmental Testing - CubeSats}

The functional tests described previously are undertaken throughout the environmental campaign. Both CubeSats and deployers initially underwent a range of individual environmental testing including mechanical (vibration) and thermal. After the CubeSat and deployer are brought together and the deployer

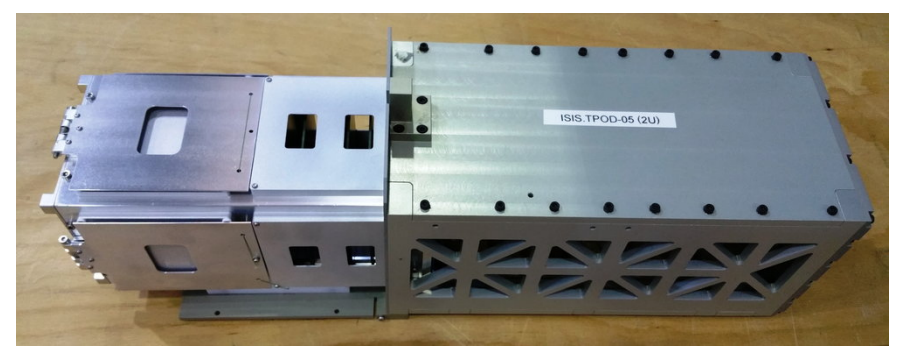

Fig. 15: DS-2: Vibration EVT Testing. 
spring tuning is done, the combined payload progresses through a further thermal cycling test (with CRS release) and a functional system end to end test (SEET) under vacuum. A final combined acceptance vibration test is performed before delivery to the platform for integration.

The setup for the initial CubeSat vibration testing can be seen in Figure 15, where the CubeSat is shown being inserted into the deployer TestPod.

\subsection{Environmental Testing - Deployer and CRS}

Both ISIPOD and CRS were subjected and successfully passed the qualification vibe (see Figure 16) and thermal tests according to ISIS general levels that cover all the RemoveDebris loads profiles.

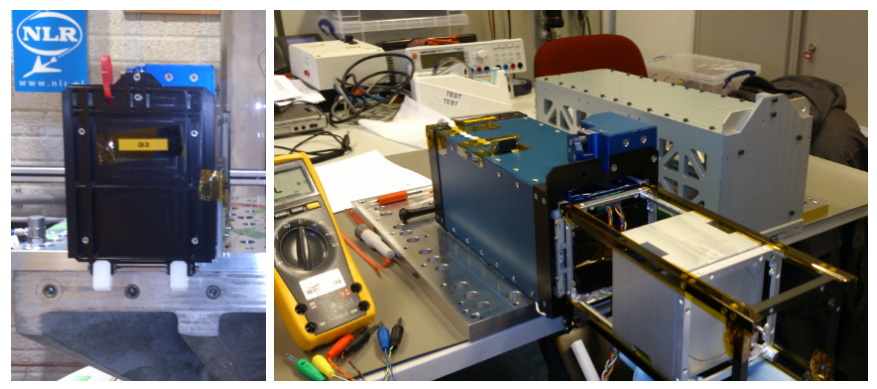

Fig. 16: Deployer and CRS: Vibration EVT Testing. Shows ISIPOD during vibration test and during functional test after vibration test.

In addition both ISIPOD and CRS are subjected to shock measurement in order to measure the shock environment created on the CubeSat due to the different shock events during operations and to ensure requirement R18 is met. Figure 17 shows the test setup for shock on a $2 \mathrm{U}$ dummy mass, showing the ISIPOD (in blue), 2U frame (in black) and dummy mass (in grey). Figure 18 shows the test results showing the SRS (generic survivable shock load for the launcher) and the measured shock from a CubeSat ejection event. The measured shocks are lower than the SRS levels showing the magnitude of the ejection event is sufficiently low to not be of concern.

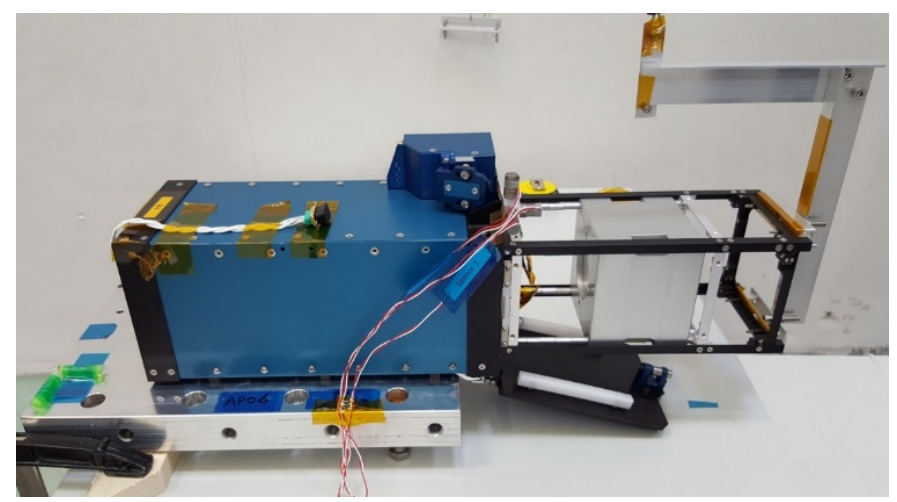

Fig. 17: Deployer and CRS: Shock EVT Testing. Shows the shock measurement test setup.

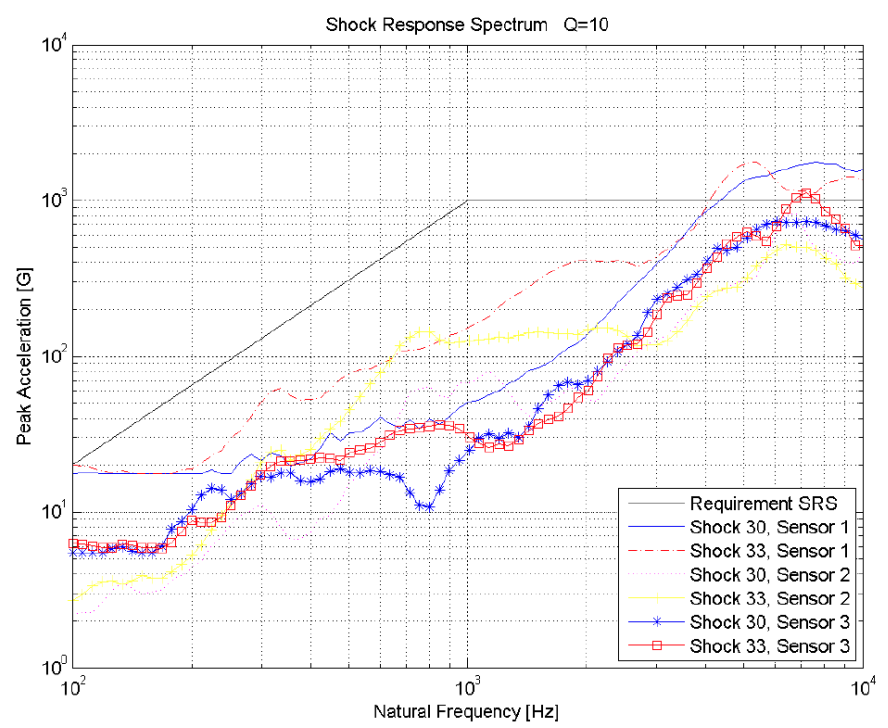

Fig. 18: Deployer and CRS: Shock EVT Testing. Shows one of the shock measurements.

\section{Payloads - Net}

The Net Capture Payload Flight Model was assembled and successfully acceptance tested in 2016. The acceptance tests comprised functional testing, vibration testing and thermal vacuum testing. The functional testing was done just after integration and before and after each environmental test to verify proper functionality. The test simulated the complete mission sequence of the Net Capture Payload including ejection of lid and net and closure of net via motors.

\subsection{Functional Testing}

Extensive functional testing has been covered in past research, namely the net deployment on both a Novespace A300 parabolic flight and within the Bremen drop tower; such experiments helped verify requirements R5 and R6. From a functional perspective, once the net hits the target, a series of counterweights with enclosed motors will wrap around the target and will reel in to encapsulate the target. This performance has been demonstrated both in simulation and in functional testing. Further information can be found in $[1,44]$.

\subsection{Environmental Testing}

The test setup for the vibration test is shown in Figure 19. The system is flight configuration including beta cloth thermal cover. Vibration sensors to measure input (pilot P-1 and P-2) are shown as well as a sensor on the flight model. The test included low level resonance search runs, random testing as well as low frequency sine quasi-static testing.

After vibration testing, a thermal vacuum test at minus 20 degrees and plus 50 degrees Celsius was performed. At temperature extremes the net was ejected in vacuum and the proper deployment was verified. The Net Capture Payload is now ready for integration. Mating with the satellite bus and system testing is expected later in 2017. 


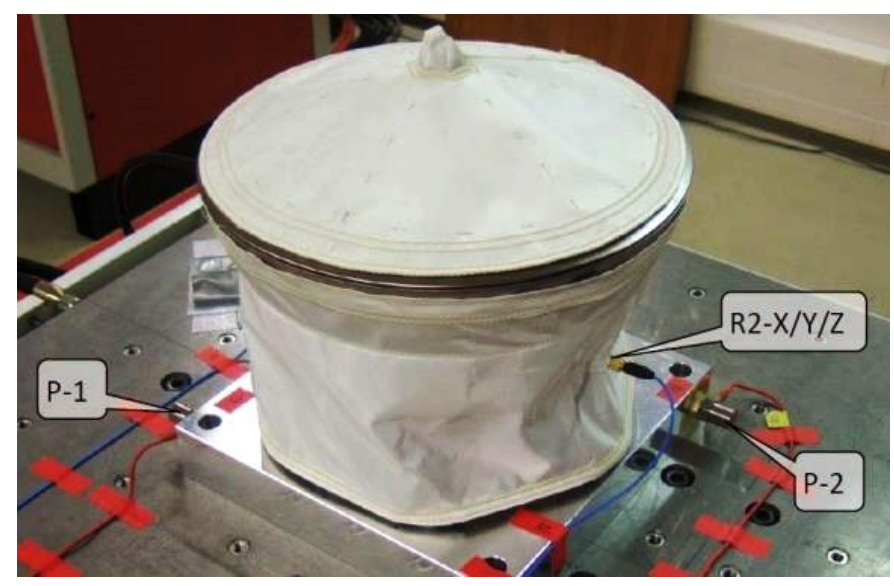

Fig. 19: Net: Vibration EVT Testing.

\section{Payloads - Harpoon}

The harpoon development has progressed from [1] with the addition of a second cold gas generator (TNO) and the associated modifications (electrical, mechanical sizing). The harpoon chassis and boom are now delivered for the PFM build. The proto-flight hardware is not yet assembled, but key testing has been undertaken to verify the critical performance aspects of the design. The final structure can be seen in Figure 20.

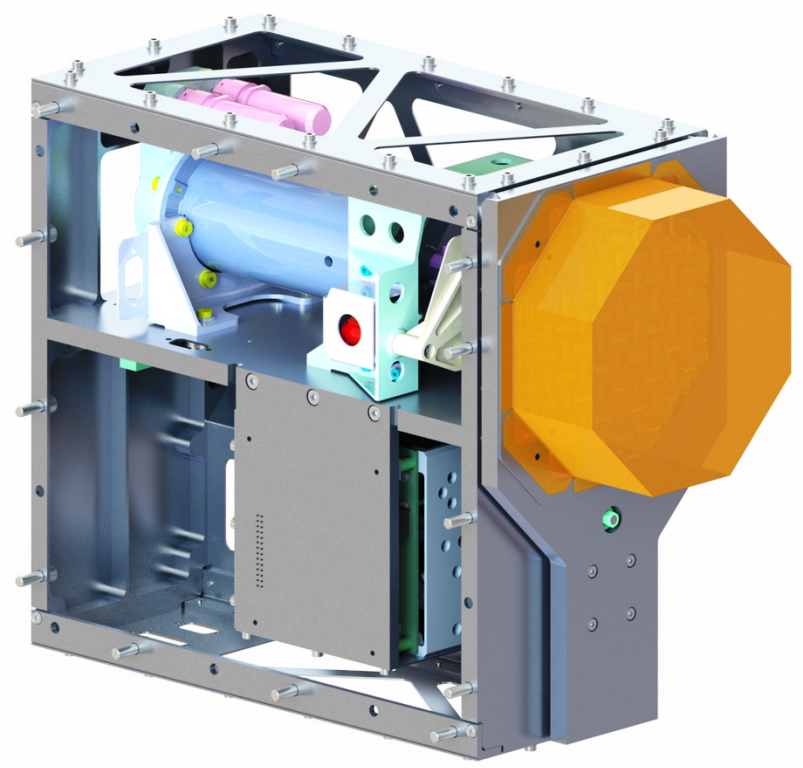

Fig. 20: Harpoon: Overall System including Target Assembly Showing: harpoon chamber and mountings (blue, cyan), CGGs (pink), frangibolt (red), OSS boom unit (green), Kapton box (yellow).

\subsection{Functional Testing - Snail Test}

The harpoon projectile imparts significant energy into the target material when impacting, even allowing for the energy lost in penetrating the honeycomb panel material. This excess energy (typically up to $20 \mathrm{~J}$ ) may be transmitted back through the boom structure. Testing has been conducted to evaluate approaches to absorb this energy, in order to protect the boom. Experiments with flexible couplings between boom and target have been evaluated, as shown in the test in Figure 21. This is the first part of verification of requirements R7 (target tilt), R8 (target material), and R9 (target distance).

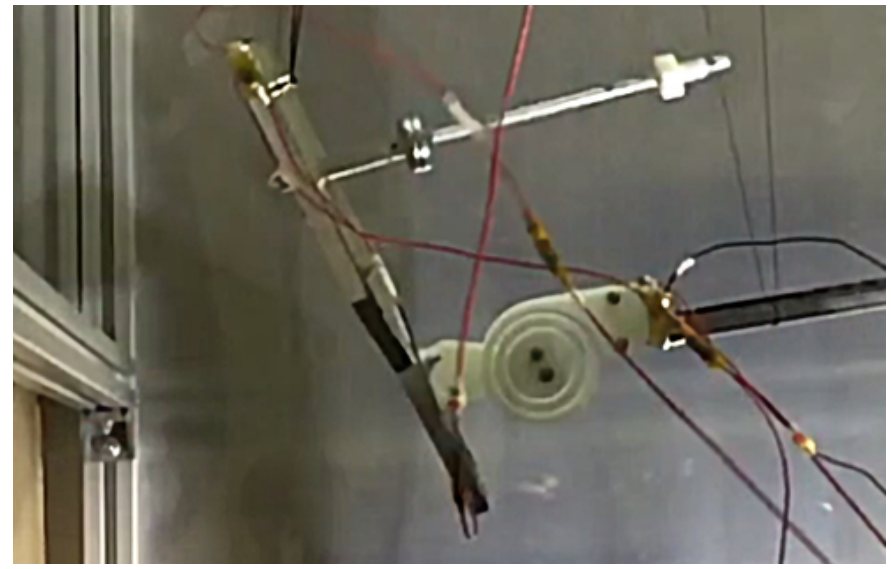

Fig. 21: Harpoon: Snail Test. Shows testing with brackets that absorb the shock energy. Showing: harpoon projectile, target frame, end of boom, flexible absorption system and gravity assist lines.

\subsection{Functional Testing - Tether Test}

A successful harpoon experiment will result in the projectile embedding itself in the target - however in the event that the harpoon projectile misses or rebounds from the target the projectile must be restrained to avoid space debris. A $2 \mathrm{~mm}$ diameter Dyneema tether design has been tested to verify the ability to dynamically restrain the harpoon. The results show (see Figure 22) that the spliced ends of the tether allow some slippage through (up to $30 \mathrm{~mm}$ ) before the braid splice tightens.

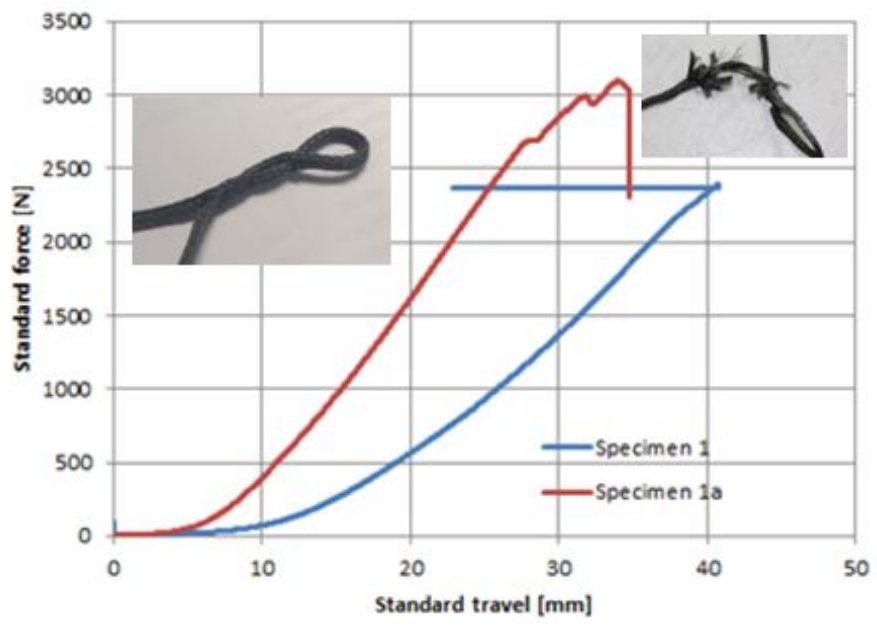

Fig. 22: Harpoon: Tether Test. Tether characterisation, showing extension and point of fracture. 
Subsequent retest results in lower extension values. The tether tensile strength was demonstrated to have positive margins of safety. At fracture point the tether design failed at the point of the first splice, indicating that the splicing introduces weakness resulting in an overall strength less than that of the raw braid material.

\subsection{Functional Testing - Flight Test}

Preparation of the test environment for the flight hardware has been performed, with the new tether design and setting up the test facility with representative (in-orbit) lighting levels. The ambient light levels have been established $\left(1700 \mu \mathrm{W} / \mathrm{cm}^{2}\right.$ visible bandwidth), within the ground test environment to ensure adequate visibility of the projectile $100 \mathrm{~ms}$ flight time with observation cameras. The projectile deployment has been observed to verify correct operation and deployment of the tether slide and tether storage on the spools has been observed to ensure deployment during the early flight phase. Figure 23 demonstrates such a test, which helps complete the verification for requirements R7 to R9.

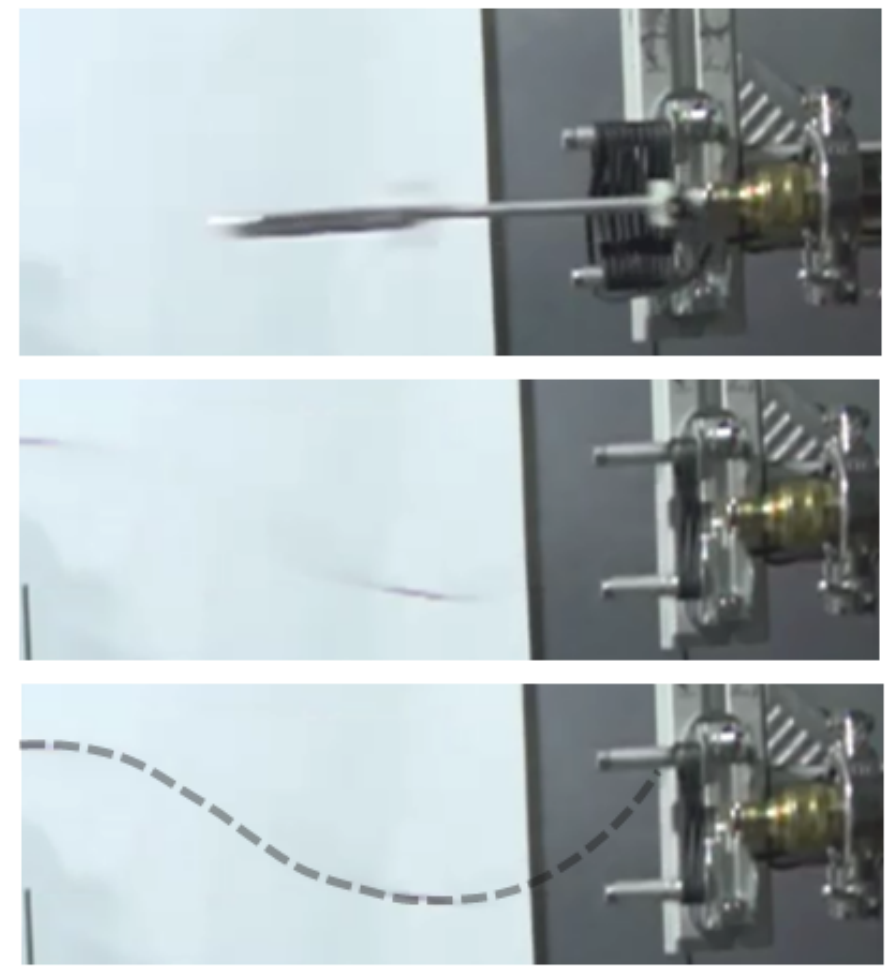

Fig. 23: Harpoon: Flight Test. Top: the tether slide is correctly collected by the projectile as it leaves the housing. Middle: tether is deployed - note the snaking of the tether (left side of image) as it is pulled from the storage spools. Lower: addition of the tether line trajectory from the middle image for clarity.

\subsection{Functional Testing - Tear-Pin Test}

A critical aspect of the harpoon is the point at which the projectile is released - this is dictated by the gas pressure acting on the piston. The release point is determined by a tear-pin design that is designed to tensile-fracture at a given load. Testing on several pin designs has been performed to validate the design and selection for the Harpoon. On the basis of these results the flight design part has now been selected. Figure 24 shows some of the results from the tear-pin test.

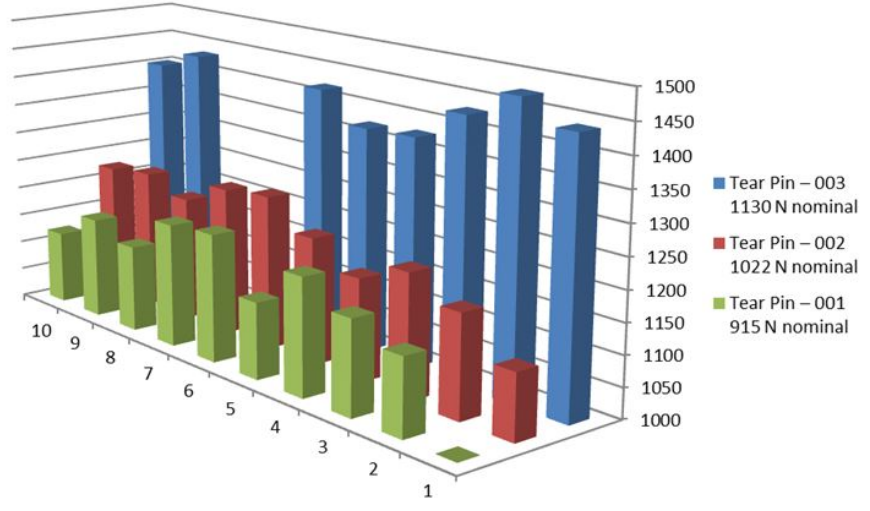

Fig. 24: Harpoon: Tear-Pin Test. Showing fracture loads in $N$ for 3 different tear-pin designs (green, red and blue) for 10 repeated experiments.

\section{Payloads - Vision-based Navigation (VBN)}

The Vision-Based Navigation is an experiment of proximity navigation between the satellite platform and an CubeSat DS-2. At the beginning of the experiment DS- 2 will be ejected by the platform and will drift gently away for several hours.

The main goal of the experiment is to evaluate navigation algorithms and a VBN sensor. Dedicated image processing and navigation algorithms have indeed been designed at Airbus Defence and Space and INRIA to meet the specific case of non-cooperative rendezvous [20]. Airbus Defence and Space is responsible for the overall VBN experiment and the navigation algorithms, while CSEM is in charge of the sensor.

The sensor has two main subsystems: an off-the-shelf color camera and a flash imaging Light Detection And Ranging device (LiDAR) developed by CSEM. Its main functionality is to capture images of DS-2 with both vision-based devices according to a predefined timeline defining snapshot times and integration times. It is foreseen to use the VBN payload for the harpoon, net and VBN experiments. The VBN sensor has the most complex set of functionalities and interface with the platform amongst the payloads. A proto-flight model (PFM) has been made for the project as can be seen in Figure 25.

\subsection{Functional Testing - Camera and LiDAR Testing}

A set of functional tests have to be conducted with the VBN sensor PFM aiming at taking images with the camera and the LiDAR, and uploading these images from the sensor to a unit simulating the platform PIU (see Table 2).

The VBN sensor has 5 modules: a communication and power interface module, a core processing unit (CPU) with $2 \mathrm{~GB}$ of flash memory, a VCSEL laser source, a $160 \times 120$ time-of-flight receiver module $($ TOF $\mathrm{RX}$ ) and a $2048 \times 1536$ camera module. The camera module has also $2 G B$ of local flash memory. The CPU and the camera are off-the-shelf COTS products. All the other modules have been designed and fabricated by CSEM. 


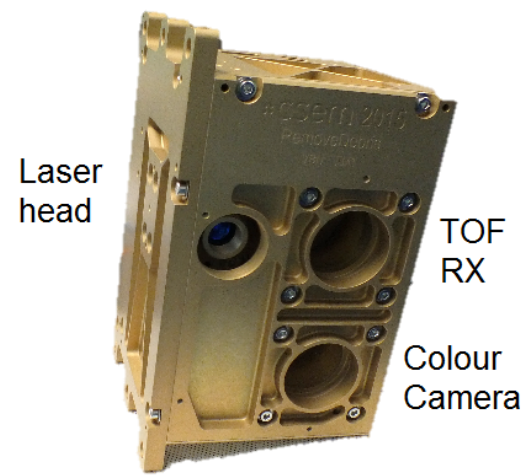

Fig. 25: VBN: Sensor PFM.

To get all the functionalities of the VBN sensor, 3 firmware running in full synchronisation respectively on the CPU, on the TOF RX and in the camera have been implemented. 3 communication interfaces must be managed by the CPU: the CPU-TOF RX, the CPU-camera and the CPU-PIU. Each of them has its own communication protocol. The CPU-TOF RX is a three signals serial interface. The CPU-camera is a CAN bus. The CPU-PIU is SPI interface with LVDS electrical levels.

A breadboard test setup can be seen in Figure 26 that shows communication with a PIU emulation and verifies requirement R12.

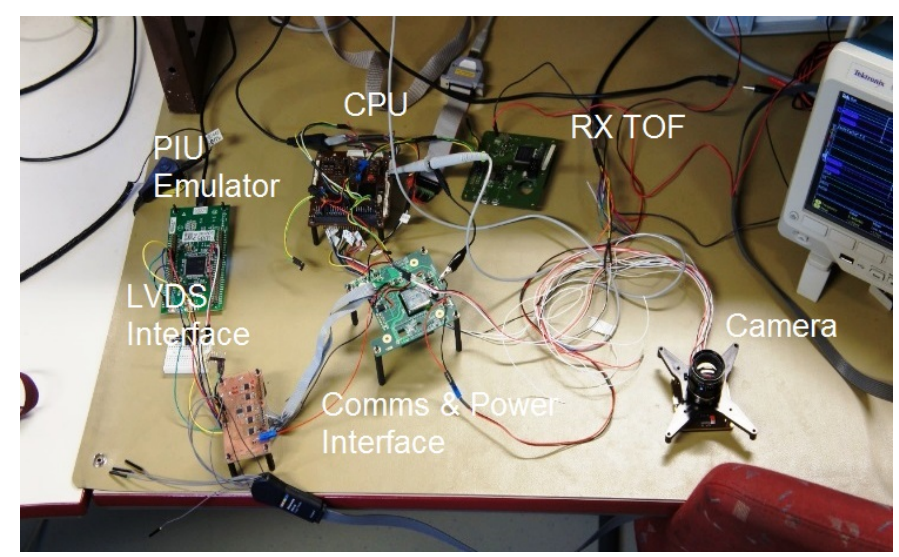

Fig. 26: VBN: Sensor Modules in Breadboard Test. Laser and TOF RX optics not present.

Figure 27 presents an image captured with the camera. The respective distance of the targets are quoted on the image. Figure 28 presents the same scene captured with the LiDAR. The LiDAR provides 2 images: a B\&W intensity image similar to any standard camera, and a distance image or depth map that is a $3 \mathrm{D}$ image of the scene of interest or target. Requirements R10 and R11 are verified by ensuring the hardware is capable of collecting the requisite number of images.

The way in which the VBN algorithms are validated with respect to the VBN experiment and the tracking performance is investigated in [20].

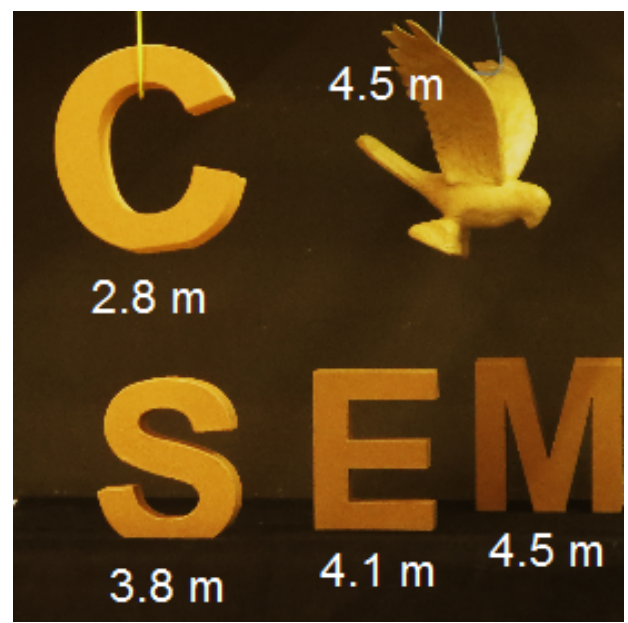

Fig. 27: VBN: Image from Camera. Using the letters 'CSEM' from the partner's name. Provides an indication of the targets' distances.
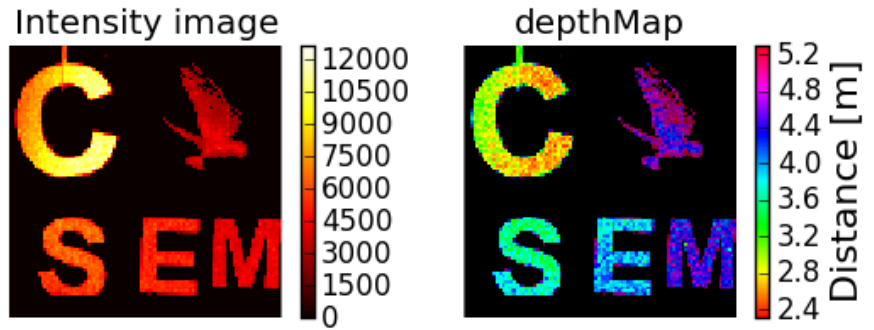

Fig. 28: VBN: Image from LiDAR. Left: showing image intensity in number of visible photons (more yellow objects are brighter). Right: 3D depthmap scene in metres.

\subsection{Environmental Testing}

The payloads EVT conditions are defined by the platform and mission systems. The PFM endures mechanical random and combined sine and quasi-static, thermal vacuum and EMC tests prior to delivery. EVT was conducted, in the first place, individually on the various subsystems of the sensor. After the complexion of the functional tests, the whole system was assessed. The TVAC tests are shown in Figure 29 and the results are presented in Figure 30 showing successful results.

Following EVT, and before delivery, the PFM will have to be calibrated. The goal is to determine the geometrical parameters of both vision-based subsystems to correct optical aberrations.

\section{Payloads - Dragsail}

This section will focus on the testing of the dragsail, both functional and environmental, which is a version of the system used on the InflateSail mission. The dragsail consists of two parts, an inflatable mast and a sail deployment mechanism. The stacked FM, ready for final flight preparation, is visible in Figure 31 , where the bottom part is the sail deployment mechanism with deployable carbon fibre booms, the middle is the sail material that is drawn out during sail deployment, and the top part is the inflatable mast that is deployed using a CGG. Further testing details can be found in [45]. 


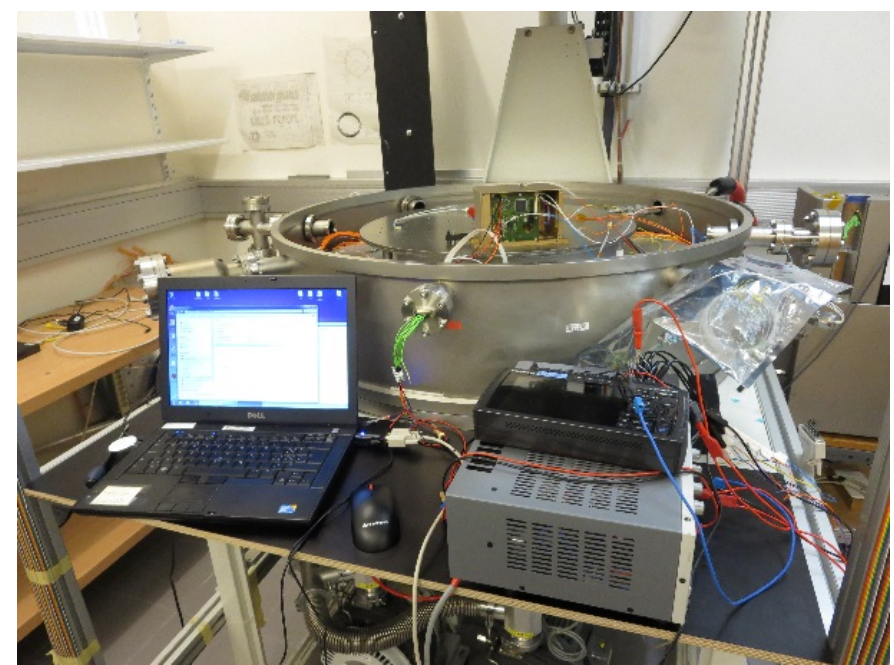

Fig. 29: VBN: TVAC EVT Testing. Showing testing of the TOF RX.

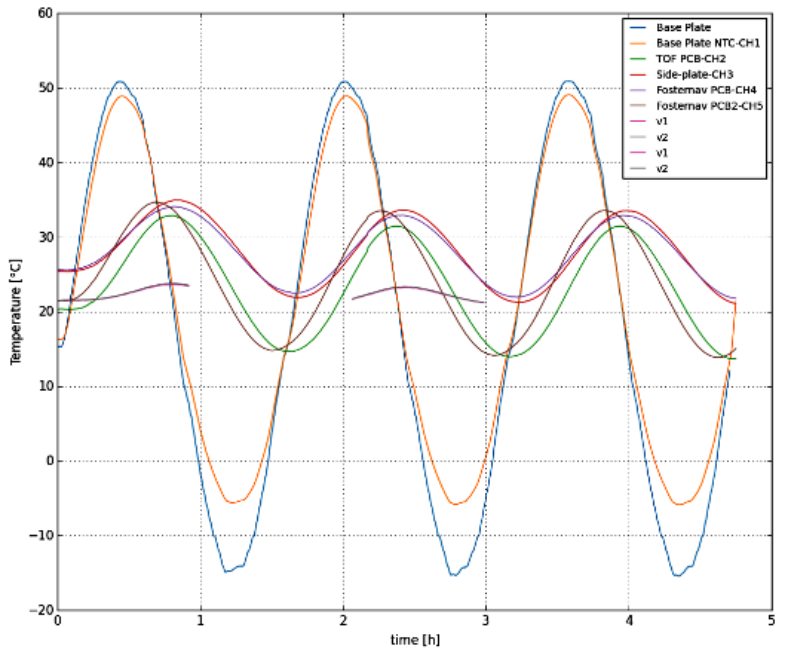

Fig. 30: VBN: Thermal Cycles. Showing TVAC test results with 3 orbits of $1.5 \mathrm{~h}$.

\subsection{Functional Testing - Inflation and Sail Deployment}

Several functional tests were performed in inflating the boom and deploying the sail. Initially, inflatable deployment was tested for maximum pressure, under gravity compensation, with a Mylar bladder and finally using a balloon. The balloon test is shown in Figure 32 and shows how the balloon is used as a gravity offloading system. The removal of the major creases in the skin was clearly observed, showing boom rigidisation.

Figure 33 shows one of the full deployment tests of both mast and sail showing size compliance with requirements R13 and R14.

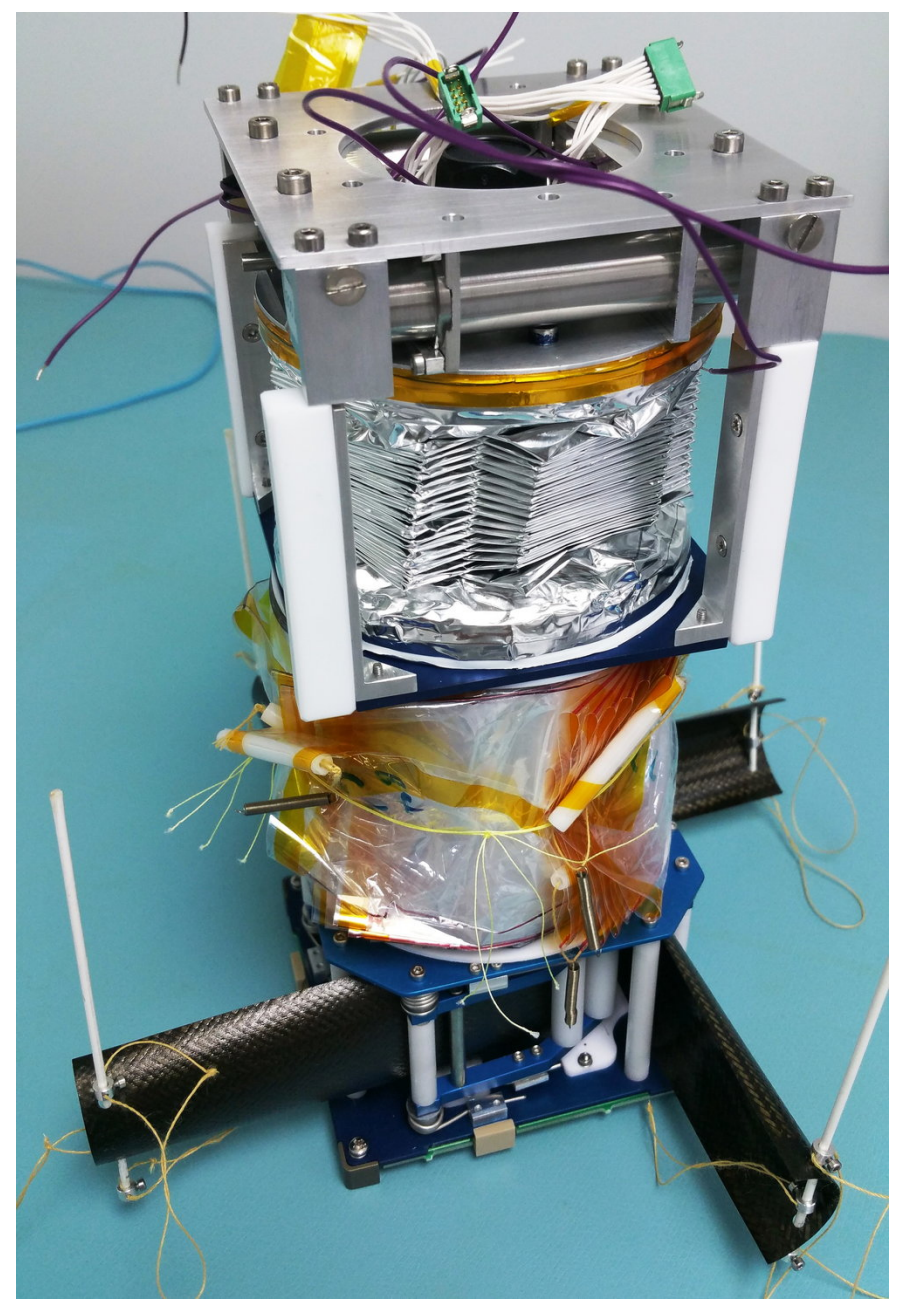

Fig. 31: Dragsail: Assembled Flight Payload.
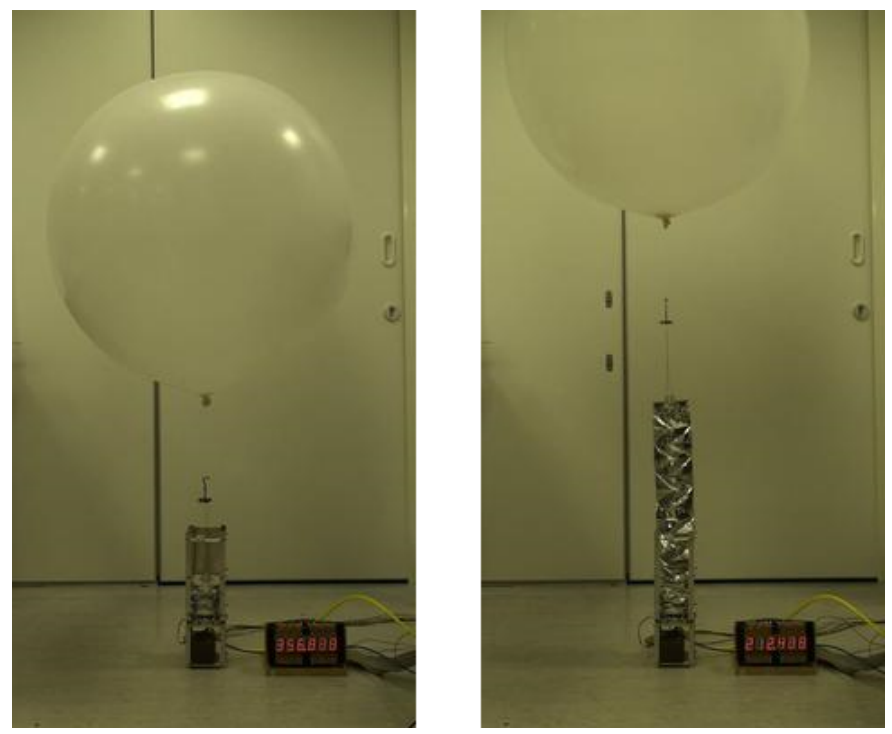

Fig. 32: Dragsail: Inflation Test with Balloon Assist. With EQM unit.

\subsection{Environmental Testing}

A full complement of environmental testing including vacuum, vibration and thermal were performed. 


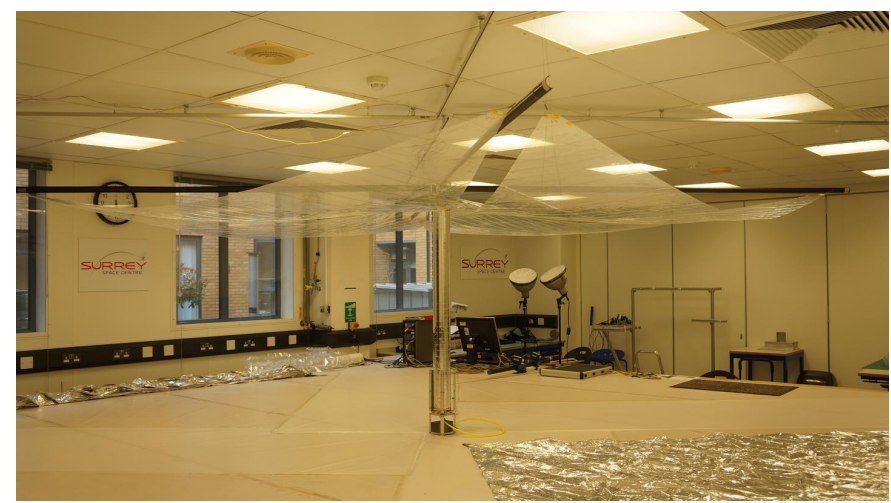

Fig. 33: Dragsail: Deployment Test. With EQM unit.

The purpose of the vacuum environmental testing was twofold. One of the aims was to assess the likelihood of a pressure build-up during ascent to simulate the launch phase and to ensure the solenoid venting valve was correctly operating (the solenoid valve is a normally-open type, so the stowed boom is free to vent until the valve is powered). Secondly, the test helped ensure that the system is airtight in space (a vacuum). The testing is visible in Figure 34. During the vacuum testing, a full deployment of the mast was undertaken.

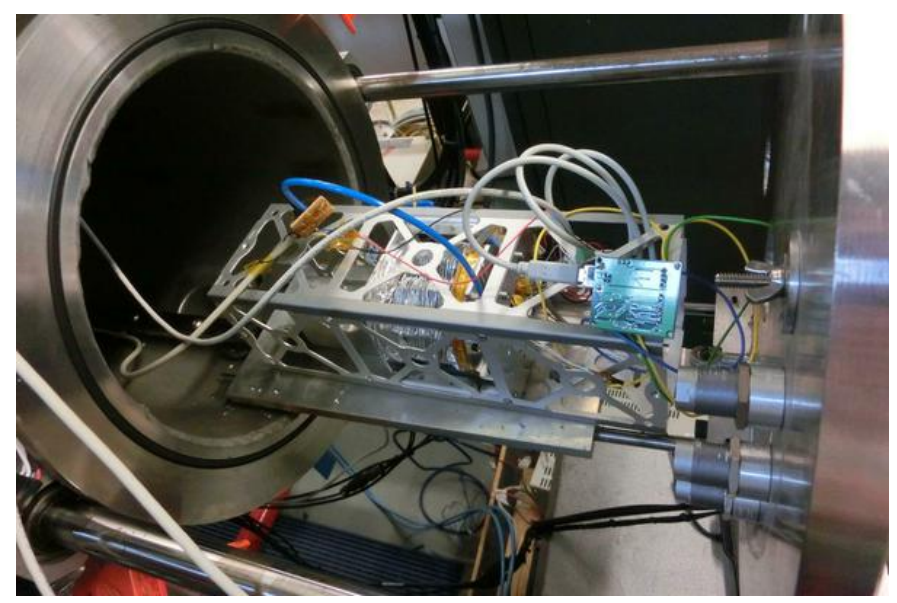

Fig. 34: Dragsail: Vacuum EVT Testing. With EQM unit.

As visible in Figure 35, the dragsail was tested in vibration on all axes, performing: low level sine sweep, short sine sweep, sine sweeps, random. All tests were successful and there was no visible damage on physical inspection.

As visible in Figure 36, in thermal tests, the dragsail was tested for greater than 1 hour at both minus 20 degrees and plus 50 degrees Celsius. The thermal cycle is shown in Figure 37 where three temperature probes were used: ambient, internal to satellite, table-top. Following the thermal test, a full inflatable functional test was performed.

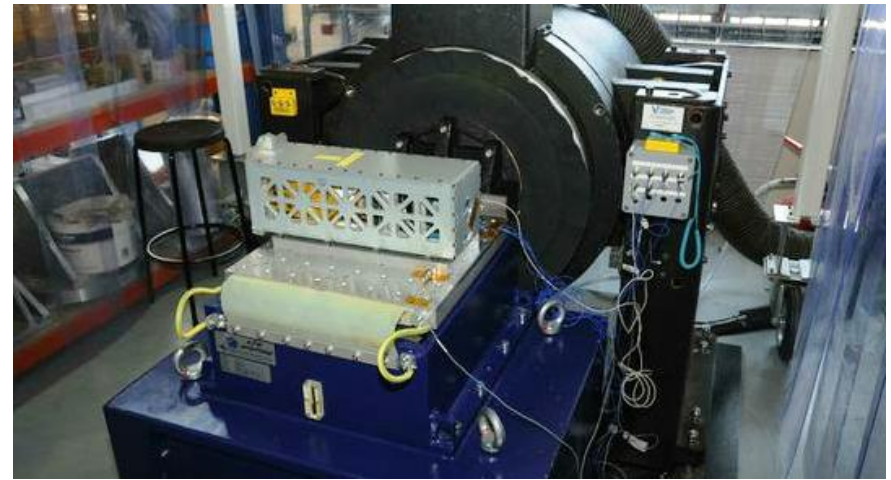

Fig. 35: Dragsail: Vibration EVT Testing. With EQM unit.

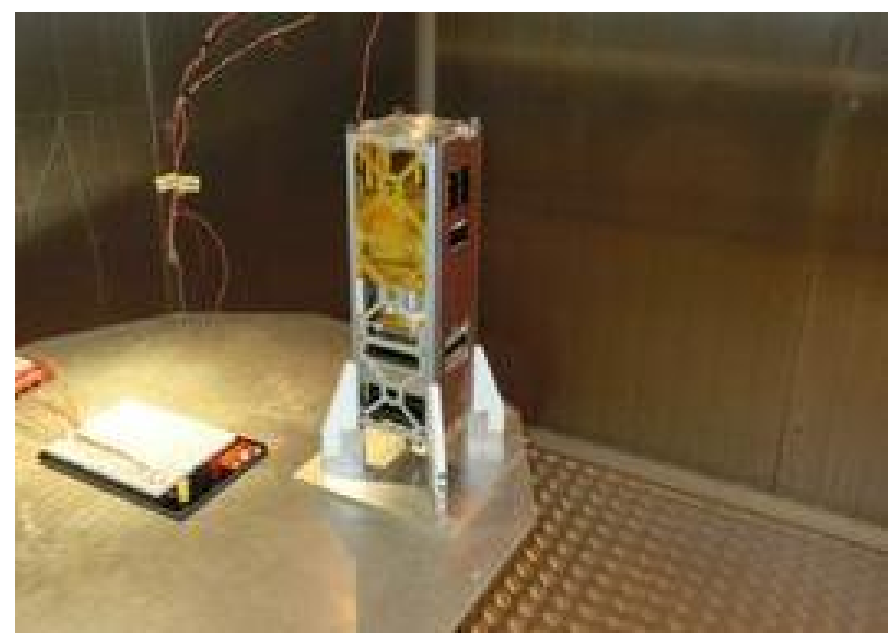

Fig. 36: Dragsail: Thermal EVT Testing. With EQM unit.

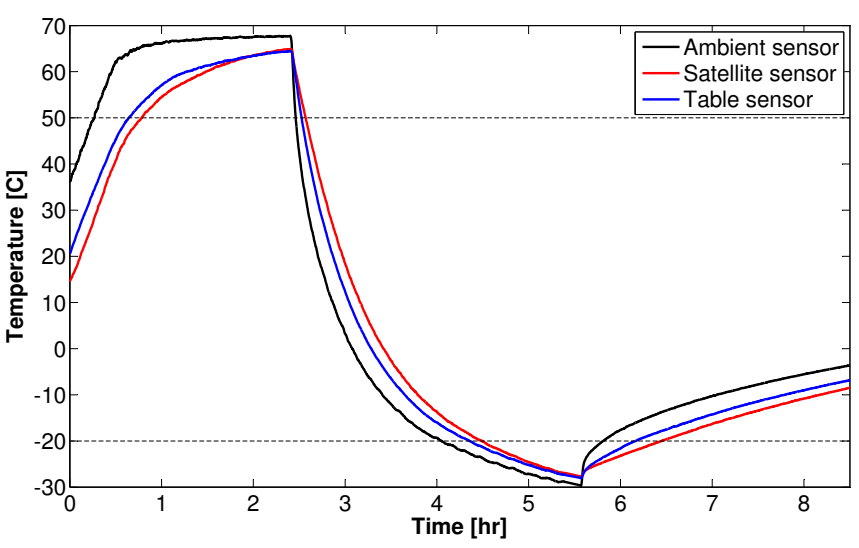

Fig. 37: Dragsail: Thermal Cycles. 


\section{Conclusions}

RemoveDebris is aimed at performing key ADR technology demonstrations (e.g capture, deorbiting) representative of an operational scenario during a cost effective mission using novel key technologies for future missions in what promises to be one of the first ADR technology missions internationally. The mission aims to be the first mission to demonstrate the use of a harpoon and net in space for debris capture, and the first use of CubeSats as 'artificial debris' targets. Additionally, the mission will be the world's first $100 \mathrm{~kg}$ satellite to be launched from the ISS.

This paper has provided an insight into the testing of the payloads for the mission. In particular, the launch peculiarities, the testing philosophy and the type of tests performed across the payloads were explored.

The key ADR technologies include the use of net and harpoon to capture targets, vision-based navigation to target debris and a dragsail for deorbiting. Although this is not a fully-fledged ADR mission as CubeSats are utilised as artificial debris targets, the project is an important step towards a fully operational ADR mission; the mission proposed is a vital prerequisite in achieving the ultimate goal of a cleaner Earth orbital environment.

\section{Acknowledgements}

This research is supported by the European Commission FP7-SPACE-2013-1 (project 607099) 'RemoveDebris - A Low Cost Active Debris Removal Demonstration Mission', a consortium partnership project consisting of: Surrey Space Centre (University of Surrey), SSTL, Airbus DS (formerly Astrium) $\mathrm{GmbH}$, Airbus SAS, Airbus Ltd, Airbus Safran Launchers, Innovative Solutions in Space (ISIS), CSEM, Inria, Stellenbosch University.

\section{References}

[1] J. L. Forshaw, G. S. Aglietti, N. Navarathinam, H. Kadhem, T. Salmon, A. Pisseloup, E. Joffre, T. Chabot, I. Retat, R. Axthelm, S. Barraclough, A. Ratcliffe, C. Bernal, F. Chaumette, A. Pollini, W. H. Steyn, RemoveDEBRIS: An in-orbit active debris removal demonstration mission, Acta Astronautica 127 (2016) 448 - 463. doi:10.1016/j.actaastro.2016.06.018.

[2] R. Biesbroek, A. Wolahan, Maturing the technology for ESA's e.Deorbit mission to remove a large, heavy space debris from low earth orbit, in CNES 4th International Workshop on Space Debris Modelling and Remediation, Paris, France, 2016.

[3] L. Innocenti, Clean space - an overview, in: ESA Clean Space Industrial Days, ESTEC, Netherlands, 2016.

[4] C. Saunders, J. L. Forshaw, V. J. Lappas, A. Chiesa, B. Parreira, R. Biesbroek, Mission and systems design for the debris removal of massive satellites, in: 65th International Astronautical Congress, Toronto, Canada, 2014.

[5] C. Saunders, J. L. Forshaw, V. J. Lappas, D. Wade, D. Iron, R. Biesbroek, Business and economic considerations for service oriented active debris removal missions, in: 65th International Astronautical Congress, Toronto, Canada, 2014.

[6] S. Estable, Envisat removal by robotic capture means - results of the airbus ds led e.Deorbit Phase B1 ESA study, in: ESA Clean Space Industrial Days, ESTEC, Netherlands, 2016.

[7] M. Scheper, e.deorbit Phase B1 System Overview (OHB), in: ESA Clean Space Industrial Days, ESTEC, Netherlands, 2016.
[8] C. Cougnet, B. Gerber, C. Heemskerk, K. Kapellos, G. Visentin, Onorbit servicing system of a GEO satellite fleet, in: 9th ESA Workshop on Advanced Space Technologies for Robotics and Automation 'ASTRA 2006', ESTEC, Netherlands, 2006.

[9] A. Pisseloup, T. Salmon, C. Cougnet, M. Richard, ADR concepts from CNES funded study OTV, in: 64th International Astronautical Congress, Beijing, China, 2013.

[10] D. Reintsema, B. Sommer, T. Wolf, J. Theater, A. Radthke, W. Naumann, P. Rank, J. Sommer, DEOS - the in-flight technology demonstration of german's robotics approach to dispose malfunctioned satellites, in: ESA 11th Symposium on Advanced Space Technologies in Robotics and Automation, ESTEC, Netherlands, 2011.

[11] Astrium Space Transportation, ROGER Phase-A Final Report Executive Summary, Tech. Rep. ROG-SIBRE-EXS, Astrium Space Transportation (2003).

[12] A. Pisseloup, S. Estable, K. Pegg, E. Ferreira, R. Delage, J.-M. Pairot, T. Salmon, A. Ratcliffe, M. Frezet, Airbus defence and space's vision and activities in active debris removal and on-orbit servicing, in: CNES 4th International Workshop on Space Debris Modelling and Remediation, Paris, France, 2016.

[13] M. Merino, E. Ahedo, C. Bombardelli, H. Urrutxua, J. Pelaez, L. Summerer, Space debris removal with an ion beam shepherd satellite: targetplasma interaction, in: 47th AIAA Joint Propulsion Conference \& Exhibit, San Diego, US, 2011.

[14] A. Parness, Orbital debris removal with gecko-like adhesives; technology development and mission design, in: 66th International Astronautical Congress, Jerusalem, Israel, 2015.

[15] C.Trentlage, E.Stoll, The applicability of gecko adhesives in a docking mechanism for active debris removal missions, in: 13th Symposium on Advanced Space Technologies in Robotics and Automation, ASTRA 2015 ESTEC, Netherlands, 2015.

[16] A. Chiesa, G. Gambacciani, D. Renzoni, G. Bombaci, Enabling technologies for active space debris removal: the CADET (CApture and DEorbiting Technologies) project, in: CNES 4th International Workshop on Space Debris Modelling and Remediation, Paris, France, 2016.

[17] M. Bicocca, Debris capture technologies overview, Tech. rep., Aviospace (May 2014).

[18] A. Petit, E. Marchand, K. Kanani., Tracking complex targets for space rendezvous and debris removal applications, in: IEEE/RSJ Conference on Intelligent Robots and Systems, IROS'12, Vilamoura, Portugal, 2012.

[19] T. Chabot, E. Kervendal, N. Despre, K. Kanani, P. Vidal, E. Monchieri, D. Rebuffat, S. Santandrea, J. L. Forshaw, Relative navigation challenges and solutions for autonomous orbital rendezvous, in: EuroGNC 2015, Toulouse, France, 2015.

[20] A. Yol, E. Marchand, F. Chaumette, K. Kanani, T. Chabot, Vision-based navigation in low earth orbit, in: i-SAIRAS 2016, Beijing, China, 2016.

[21] A. Sonnenburg, Image recognition and processing for navigation (irpn), in: ESA Clean Space Industrial Days, ESTEC, Netherlands, 2016.

[22] N. Deslaef, J. Christy, Rendezvous sensors and navigation, in: ESA Clean Space Industrial Days, ESTEC, Netherlands, 2016.

[23] Jena-Optronik, The rvs3000 and rvs3000-3d lidar sensors for rendezvous and docking and space robotics, in: ESA Clean Space Industrial Days, ESTEC, Netherlands, 2016.

[24] J. L. Forshaw, C. Massimiani, M. Richter, A. Viquerat, E. Simons, R. Duke, G. Aglietti, Surrey Space Centre: A survey of debris removal research activities, in: 66th International Astronautical Congress, Jerusalem, Israel, 2015 .

[25] P. Voigt, C. Vogt, B. Barthen, H. Stokes, C. Underwood, A. Knoll, K. Ryden, M. Macdonald, E. Kerr, et. al., TeSeR - technology for self-removal a horizon 2020 project to ensure the post-mission-disposal of any future spacecraft, in: ESA Clean Space Industrial Days, ESTEC, Netherlands, 2016.

[26] S. Antonetti, D-SAT mission: An in-orbit demonstration of autonomous decommissioning capabilities in changing space debris mitigation requirements scenario, in: CNES 4th International Workshop on Space Debris Modelling and Remediation, Paris, France, 2016.

[27] I. A. Sanchez, D. Paris, F. Allard, N. Frischauf, The navigation and communication systems for the Automated Transfer Vehicle, in: IEEE 49th Vehicular Technology Conference, Vol. 2, 1999, pp. 1187-1192. doi:10.1109/VETEC.1999.780535.

[28] K. Yoshida, ETS-VII Flight Experiments For Space Robot Dynamics and 
Control, Vol. 271, Experimental Robotics VII, Springer, 2001.

[29] S. Clark, Japanese Cargo Ship Ends Mission after Space Debris Experiment Flounders, spaceflightnow.com, 2017.

[30] M. Richard, L. Kronig, F. Belloni, S. Rossi, V. Gass, C. Paccolat, J. Thiran, S. Araomi, I. Gavrilovich, H. Shea, Uncooperative rendezvous and docking for microsats: The case for CleanSpace One, in: 6th International Conference on Recent Advances in Space Technologies (RAST), Istanbul, Turkey, 2013.

[31] B. Gorret, L. Mtrailler, L. Moreau-Gentien, P.-A. Musli, A. Guignard, M. Richard, M. Lauria, Status of the development of the CleanSpace One capture system, in: CNES 4th International Workshop on Space Debris Modelling and Remediation, Paris, France, 2016.

[32] N. Okada, ADRAS 1: Spacecrafts EOL solutions and debris removal, in: CNES 4th International Workshop on Space Debris Modelling and Remediation, Paris, France, 2016.

[33] NanoRacks, Space station CubeSat deployment services, Tech. rep. (February 2015).

[34] The SSTL-X50 series: next generation missions, Tech. Rep. 303.790.0653, Surrey Satellite Technology Limited (November 2013).

[35] J. L. Forshaw, G. S. Aglietti, T. Salmon, I. Retat, C. Burgess, T. Chabot, A. Pisseloup, A. Phipps, C. Bernal, F. Chaumette, A. Pollini, W. H. Steyn, The RemoveDebris ADR mission: Preparing for an international space station launch, in: 7th European Conference on Space Debris, ESOC, Darmstadt, Germany, 2017.

[36] E. Joffre, J. L. Forshaw, T. Secretin, S. Reynaud, T. Salmon, A. Pisseloup, G. Aglietti, Removedebris - mission analysis for a low cost active debris removal demonstration in 2016, in: 25th International Symposium on Space Flight Dynamics (ISSFD), Munich, Germany, 2015.

[37] STELA - semi-analytic tool for end of life analysis (2017). URL logiciels . cnes.fr/content/stela

[38] DRAMA - debris risk assessment and mitigation analysis (2017). URL sdup. esoc. esa.int/web/csdtf

[39] C. Massimiani, J. L. Forshaw, G. S. Aglietti, Cubesats as artificial debris targets for active debris removal missions, in: Stardust Final Conference, ESTEC, Netherlands, 2016.

[40] J. L. Forshaw, The RemoveDebris ADR mission: Overview of cubesat 'artificial debris' targets, in: CNES 4th International Workshop on Space Debris Modelling and Remediation, Paris, France, 2016.

[41] L. Visagie, J. L. Forshaw, T. E. Frame, V. J. Lappas, W. H. Steyn, A miniaturised attitude control and determination system for the QB50 and SME-SAT missions, in: ESA Guidance, Navigation, and Control Conference, Porto, Portugal, 2014.

[42] R. Duke, C. P. Bridges, B. Steward, B. Taylor, C. Massimiani, J. Forshaw, G. Aglietti, Integrated flight and ground software framework for fast mission timelines, in: 67th International Astronautical Congress, Guadalajara, Mexico, 2016.

[43] G. Secheli, A. D. Viquerat, G. S. Aglietti, Mechanical development of a novel inflatable and rigidizable structure, in: 3rd AIAA Spacecraft Structures Conference, San Diego, US, 2016.

[44] R. Axthelm, B. Klotz, I. Retat, U. Schlossstein, W. Tritsch, S. Vahsen, Net capture system for debris removal demonstration mission, in: 7th European Conference on Space Debris, ESOC, Darmstadt, Germany, 2017.

[45] A. Viquerat, M. Schenk, B. Sanders, V. Lappas, Inflatable rigidisable mast for end-of-life deorbiting system, in: European Conference on Spacecraft Structures, Materials and Environmental Testing, Braunschweig, Germany, 2014. 